\title{
Advocating Electrically Conductive Scaffolds with Low Immunogenicity for Biomedical Applications: A Review
}

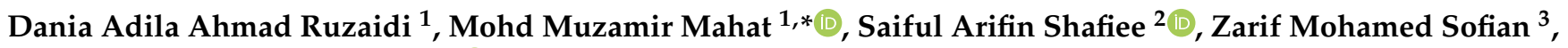 \\ Awis Sukarni Mohmad Sabere ${ }^{4}\left(\mathbb{D}\right.$, Rosmamuhamadani Ramli ${ }^{1}$, Hazwanee Osman ${ }^{5}$, Hairul Hisham Hamzah ${ }^{6}(\mathbb{D}$, \\ Zaidah Zainal Ariffin ${ }^{1, *}$ and Kishor Kumar Sadasivuni ${ }^{7, *(\mathbb{B}}$
}

check for updates

Citation: Ahmad Ruzaidi, D.A.; Mahat, M.M.; Shafiee, S.A.; Mohamed Sofian, Z.; Mohmad Sabere, A.S.; Ramli, R.; Osman, H.; Hamzah, H.H.; Zainal Ariffin, Z.; Sadasivuni, K.K. Advocating Electrically Conductive Scaffolds with Low Immunogenicity for Biomedical Applications: A Review. Polymers 2021, 13, 3395. https://doi.org/10.3390/ polym13193395

Academic Editor: Evgenia G. Korzhikova-Vlakh

Received: 1 September 2021

Accepted: 27 September 2021

Published: 2 October 2021

Publisher's Note: MDPI stays neutral with regard to jurisdictional claims in published maps and institutional affiliations.

Copyright: (c) 2021 by the authors Licensee MDPI, Basel, Switzerland. This article is an open access article distributed under the terms and conditions of the Creative Commons Attribution (CC BY) license (https:// creativecommons.org/licenses/by/ $4.0 /)$.
1 Faculty of Applied Sciences, Universiti Teknologi MARA, Shah Alam 40450, Malaysia; dniahmad1998@gmail.com (D.A.A.R.); rosma614@uitm.edu.my (R.R.)

2 Kulliyyah of Science, International Islamic University Malaysia, Bandar Indera Mahkota, Kuantan 25200, Malaysia; sabs@iium.edu.my

3 Department of Pharmaceutical Technology, Faculty of Pharmacy, Universiti Malaya, Kuala Lumpur 50603, Malaysia; ms_zarif@um.edu.my

4 Kulliyyah of Pharmacy, International Islamic University Malaysia, Bandar Indera Mahkota, Kuantan 25200, Malaysia; awissabere@iium.edu.my

5 Centre of Foundation Studies UiTM, Universiti Teknologi MARA (UiTM), Cawangan Selangor, Kampus Dengkil, Dengkil 43800, Malaysia; hazwanee@uitm.edu.my

6 School of Chemical Sciences, Universiti Sains Malaysia (USM), Gelugor 11800, Malaysia; hishamhamzah@usm.my

7 Center for Advanced Materials, Qatar University, Doha P.O. Box 2713, Qatar

* Correspondence: mmuzamir@uitm.edu.my (M.M.M.); drzaidah@uitm.edu.my (Z.Z.A.); Kishorkumars@qu.edu.qa (K.K.S.)

Abstract: Scaffolds support and promote the formation of new functional tissues through cellular interactions with living cells. Various types of scaffolds have found their way into biomedical science, particularly in tissue engineering. Scaffolds with a superior tissue regenerative capacity must be biocompatible and biodegradable, and must possess excellent functionality and bioactivity. The different polymers that are used in fabricating scaffolds can influence these parameters. Polysaccharide-based polymers, such as collagen and chitosan, exhibit exceptional biocompatibility and biodegradability, while the degradability of synthetic polymers can be improved using chemical modifications. However, these modifications require multiple steps of chemical reactions to be carried out, which could potentially compromise the end product's biosafety. At present, conducting polymers, such as poly(3,4-ethylenedioxythiophene) poly(4-styrenesulfonate) (PEDOT: PSS), polyaniline, and polypyrrole, are often incorporated into matrix scaffolds to produce electrically conductive scaffold composites. However, this will reduce the biodegradability rate of scaffolds and, therefore, agitate their biocompatibility. This article discusses the current trends in fabricating electrically conductive scaffolds, and provides some insight regarding how their immunogenicity performance can be interlinked with their physical and biodegradability properties.

Keywords: PEDOT: PSS; conducting polymer; conductive scaffolds; degradation rate; biocompatibility; fabrication of scaffolds; biomedical application; tissue engineering

\section{Introduction}

Advances in tissue engineering (TE) promise novel techniques to accelerate the recovery of damaged tissues by overcoming autologous, allogeneic, and xenogeneic tissue repair [1]. The three essential elements of TE are cells, scaffolds, and growth factors [2]. The success rate of TE is dependent on the ability of porous 3D scaffolds to mimic the function of the extracellular matrix (ECM) of a specific tissue. Scaffolds should also provide a compatible environment for the regeneration of tissues and the transplantation of organs [1,3]. Implantable scaffolds can meet the required criteria of biocompatibility, porosity, 
cell viability, and mechanical properties [4] by ensuring: (1) a greater control over the scaffold's surface topography, surface wettability and surface charge [5]; (2) an optimised scaffold's mass transportability to facilitate nutrient exchange and waste removal; (3) optimised biocompatibility to minimise the risk of toxicity [6-8]; (4) the presence of biological cues for cell fate to induce tissue regeneration [9-11]; (5) similarity in the rate of scaffold biodegradation and tissue growth $[12,13]$. The continuous development of biocompatible and biomimetic scaffolds is paramount to realise its clinical applications in improving the patient's care and quality of life [8,14].

Initially, scaffolds only act as a support system for cells to attach and proliferate. Due to this limited functionality, scaffold-based tissue engineering is primarily focused on improving tissue recovery by electrical stimuli through the application of conductive polymers (CPs). CPs exhibit electrical conductivity due to a reduction in their neutral state $[15,16]$, and because of the presence of conjugated double bonds along the backbone. Dopant ions were commonly added into the $\mathrm{CP}^{\prime} \mathrm{s}$ chemical structure to neutralise the unstable backbone of the polymer in its oxidised state by donating or accepting electrons [17]. Poly (3,4-ethylene dioxythiophene): poly (4-styrene sulfonate) (PEDOT: PSS) is an example of a biocompatible $\mathrm{CP}$ that is commonly used to produce conductive scaffolds. In another study focusing on $\mathrm{CPs}$, the electrical deterioration of scaffolds could be prevented by immobilising the dopant in a polyaniline (PANI) conductive scaffold patch. This was achieved as a result of the strong chelation bonding between a phytic acid dopant and chitosan [18] In addition, several studies have demonstrated that conductive scaffolds with polypyrrole (PPy) can promote the regeneration of nerves, bones, muscles, and cardiac cells through electrical stimulation [19]. Figure 1 shows that the electrical conduction mechanism from conductive scaffolds enables cellular signalling and function in tissues to replicate normal electrophysiology; therefore, it causes electroactive cells to align in a specific direction, as well as to migrate and proliferate. Despite the advantages of using electroactive polymers in TE, the poor biodegradability of CPs is a barrier to realising their true potential [20-23].

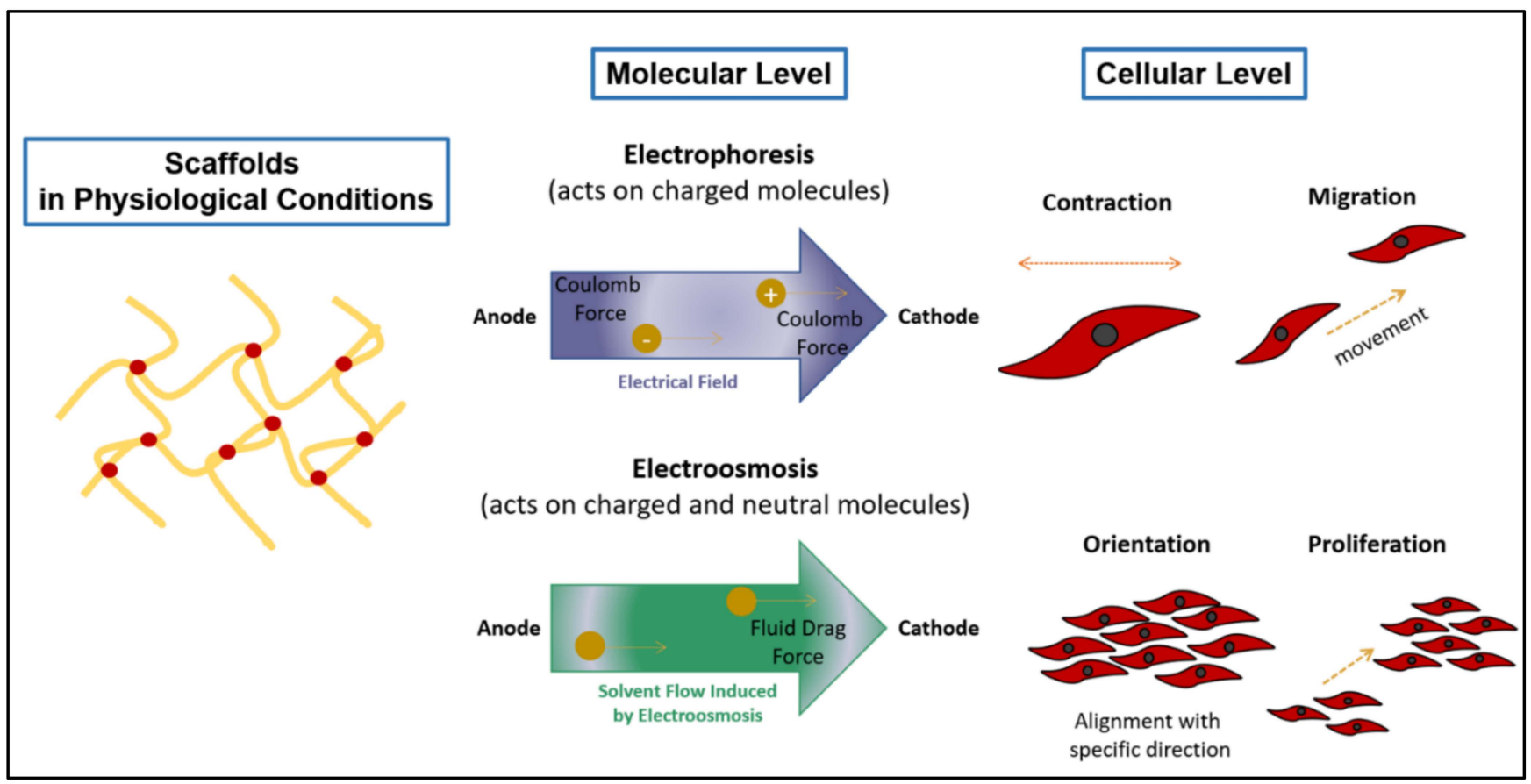

Figure 1. Illustration of the electrical conduction stimulation from conductive scaffolds, which enables cellular signalling and function in tissues.

The subject of biodegradability demands great attention in the pursuit of fabricating a conductive scaffold. The biodegradability of scaffolds is desirable, as it allows the materials to naturally dissipate, either via absorption or elimination in physiological 
conditions [24]. According to previous studies, conductive scaffolds were incorporated with natural compounds to make them biodegradable. Collagen and chitosan are examples of natural compounds that can physiologically degrade, without leaving behind any toxic residues. The application of non-toxic materials in scaffolds can minimise the adverse responses of the immune systems. However, studies on the immunogenicity performances of conductive and biodegradable scaffolds are scarce $[5,12,14,25,26]$.

It is vital to assess the efficiency of conductive scaffolds, in terms of their biodegradability and electrical conductivity. Introducing biomaterials into the human body, theoretically, triggers an immune response. However, a mild impact can be expected from a conductiveimplantable scaffold with a stable biodegradation rate, compared to the scaffolds with an unstable biodegradation rate. Regardless, the by-products of the scaffold biodegradation process should be non-toxic to the host. Toxic by-products cause excessive dead cells and damaging tissues, thus compromising the functions of organs. Therefore, the use of safer biodegradable materials with non-toxic by-products is desirable for the growth and proliferation of the cell. Figure 2 illustrates that, with the use of suitable materials, we can ideally alter the immunogenicity of scaffolds.

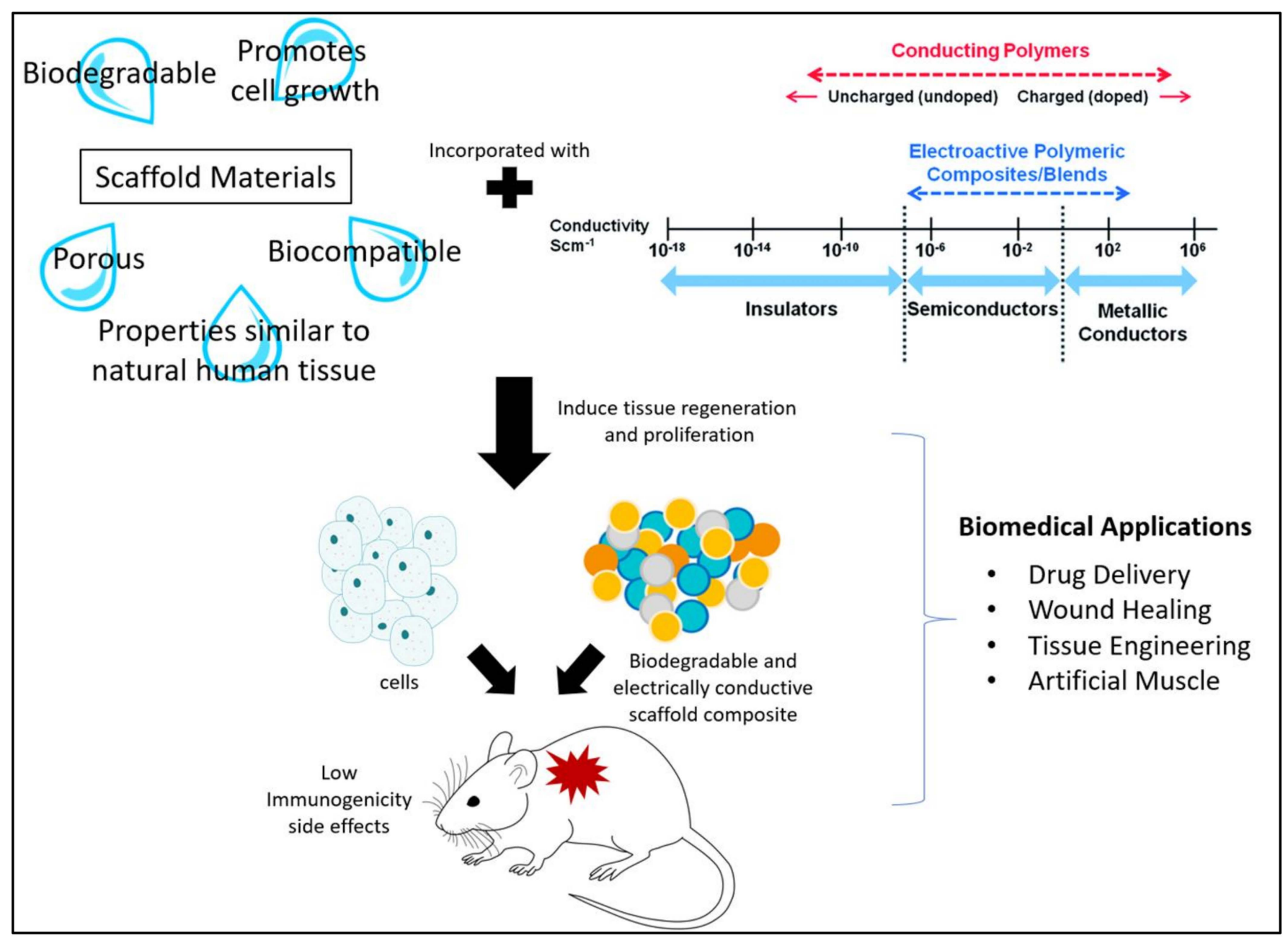

Figure 2. Illustration of the use of biodegradable and electrically conductive materials to promote cell growth with low immunogenicity. 
Although organ transplantation is a proven method to address organ complications, this method is severely limited by the difficulties in securing replacement organs from donors [11]. Scaffold-based TE could be the key to this conundrum. This review article will discuss the recent fabrication techniques that can be employed to fabricate scaffolds. The contribution of the crosslinking process in regulating the degradation rate of scaffolds will be presented. A review of scaffolds' physical properties, mainly regarding their mechanical and electrical conductivity performance, will also be discussed, according to their type of $\mathrm{CP}$ substituents. In addition, the biodegradation trends of conductive scaffolds in phosphate-buffered saline (PBS) will be reviewed, together with a juxtaposition with human immunogenic responses. Another feature of this field of research is that its outcomes can spur innovations in drug delivery processes [27]. In the latter part of this review, we outline several of the current developments of biodegradable natural materials and synthetic polymeric materials for various biomedical applications, including tissue engineering, wound healing, and drug delivery.

\section{Techniques in Fabricating Electrically Conductive Scaffolds}

The fabrication and the design of conductive scaffolds influence their performance in physiological conditions. Therefore, the required properties for a specific tissue should be identified before a scaffold is produced. The selection of materials for the scaffolds is essential to promote a safe environment for cell proliferation. Scaffolds can be fabricated from natural polymers, such as silk, collagen, keratin, cellulose, and chitin. Synthetic polymers, such as polylactic acid (PLA), polyglycolide acid (PGA), and polyhydroxyalkanoates (PHA) can also act as the base material of scaffolds. Figure 3 and Table 1 list the common techniques that are used to fabricate conductive scaffolds [17,24,28-32]. Additionally, Figure 4 shows that distinct scaffold fabrication techniques yield distinct forms and structures of scaffolds, including interconnected porous, hydrogel, and nanofibrous mat $[18,25,29,30,33]$.

At present, electrospinning and lyophilisation are two standard techniques that are used to fabricate porous scaffolds $[34,35]$. The electrospinning method is used to obtain the nanofiber. Nanofibrous structured scaffolds can resemble ECM tissues on the nanoscopic scale [14]. In order to produce an electrically conductive nanofibrous scaffold, CPs are usually mixed into the scaffold matrix using physical blending or through coating techniques. The combination of $\mathrm{CPs}$ with spinnable polymers was found to facilitate the electrospinning process, while encouraging a micro- or nano-fibre structure. A composite-conductive scaffold can be realised by adding a layer of CPs onto electrospun fibres, during the combined process of electrospinning and spin coating [25,36-38]. However, a porous scaffold that is structurally similar to foams and sponges is more stable than a nanofibrous-structured scaffold created from electrospinning. The distribution of pores in a scaffold can be rearranged randomly or by following an organised pattern. The choice of pore distribution can be accomplished by manipulating the solvent and phase separating conditions during the scaffold fabrication process. The mechanical mismatch between the host tissue and the scaffolds can be minimised by applying the best scaffold fabrication technique for the target tissue. Minimising the discrepancies in mechanical compatibility is essential to encourage the host tissue's acceptance of foreign scaffolds. 


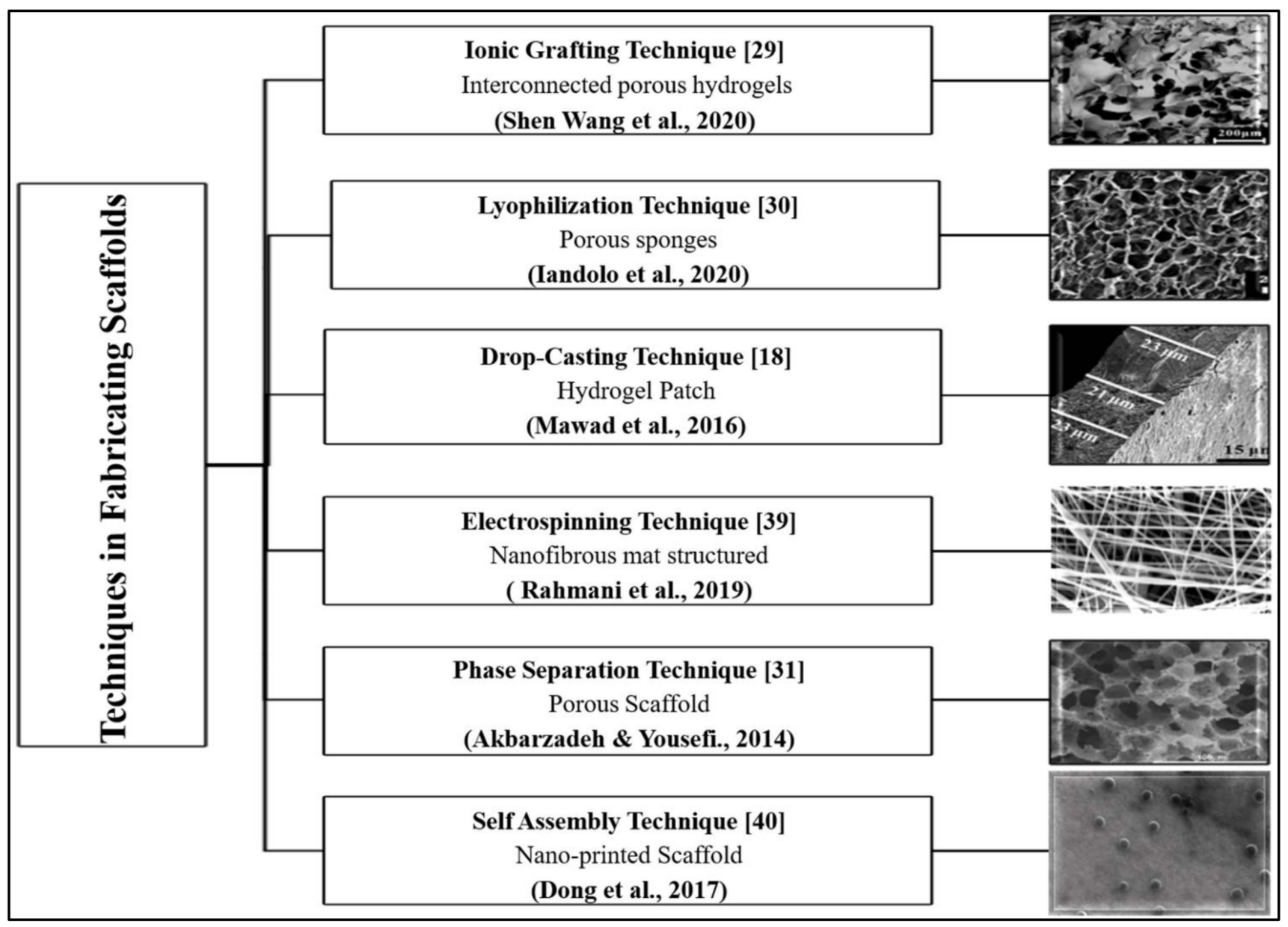

Figure 3. Techniques in fabricating scaffolds and their respective scanning electron microscope images $[18,29-31,39,40]$.

A three-dimensional (3D) composite with a high concentration of PEDOT: PSS-gelatinebioactive glass scaffold was fabricated with the freeze-drying method to promote cell response, attachment, and viability. These advantages increase the number of functional human mesenchymal stem cells (hMSC) [41]. Shen Wang et al. (2020) fabricated interconnected porous hydrogel scaffolds with an ionic grafting technique. In this technique, the conductive PPy polymer was grafted onto methacrylic anhydride gelatine in the presence of ferric ions. The reversible ionic interactions between ferric ions, the gelatine, and PPy mixtures afforded the hydrogels with self-healing abilities, injectable capabilities, and high electrical conductivity [29]. In addition, the incorporation of gelatine in scaffold composites introduced injectable capabilities, which is a valuable feature for nerve tissue regeneration. Although the biodegradation processes did reduce the electrical conductivity of the scaffolds, the scaffolds still met the minimum requirement of the electrical stimulation characteristic for application in neural TE [42,43]. A strong understanding of the interaction between cells and conductive materials is indispensable in researching smart biomaterials for their application in TE. Recently, electrically conductive hydrogels have been fabricated and designed using a 3D printing method, which includes fused deposition modelling (FDM), direct ink writing (DIW), inkjet printing, and stereolithography (SLA) methods [44]. For example, conductive polymer carbon nanocomposites as the main thermoplastic filament materials for the FDM method have been employed as emerging electrochemical sensing devices [45]. However, the main drawback of 3D printing methods is the low printing resolution that is produced at the end of the fabrication process.

Mawad et al. (2016) reported that the electrical stability of the PANI scaffold patch could be improved by immobilising the dopant, phytic acid, together with a PANI on 
the surface of a biocompatible chitosan film [18]. The PANI patch scaffold was prepared by drop-casting chitosan solution onto a glass slide, followed by drop-casting a mixture of aniline, phytic acid, and ammonium persulfate onto the chitosan film. The ability of the scaffold patch to sustain its conductive state under physiological conditions can instigate an electronic interface between the biomaterials and the implantation site. A dopant is typically introduced during the synthesis of CPs, to produce favourable electrical characteristics. Dimethyl sulfoxide (DMSO), ethylene glycol (EG), sulfuric acid $\left(\mathrm{H}_{2} \mathrm{SO}_{4}\right)$, phytic acid, and $p$-Toluenesulfonic acid ( $p$ TSA) are commonly employed as dopants [46-54]. In their research of crosslinked porous 3D hydrogel-PEDOT CP scaffolds, Mawad et al. (2016) mixed all of the required chemicals, followed by a filtration process [55]. It was found that the electroactive region of the PEDOT hydrogel network was covalently bonded to a hydrophilic polymer, and could be further altered to fabricate a covalently linked polymeric network.

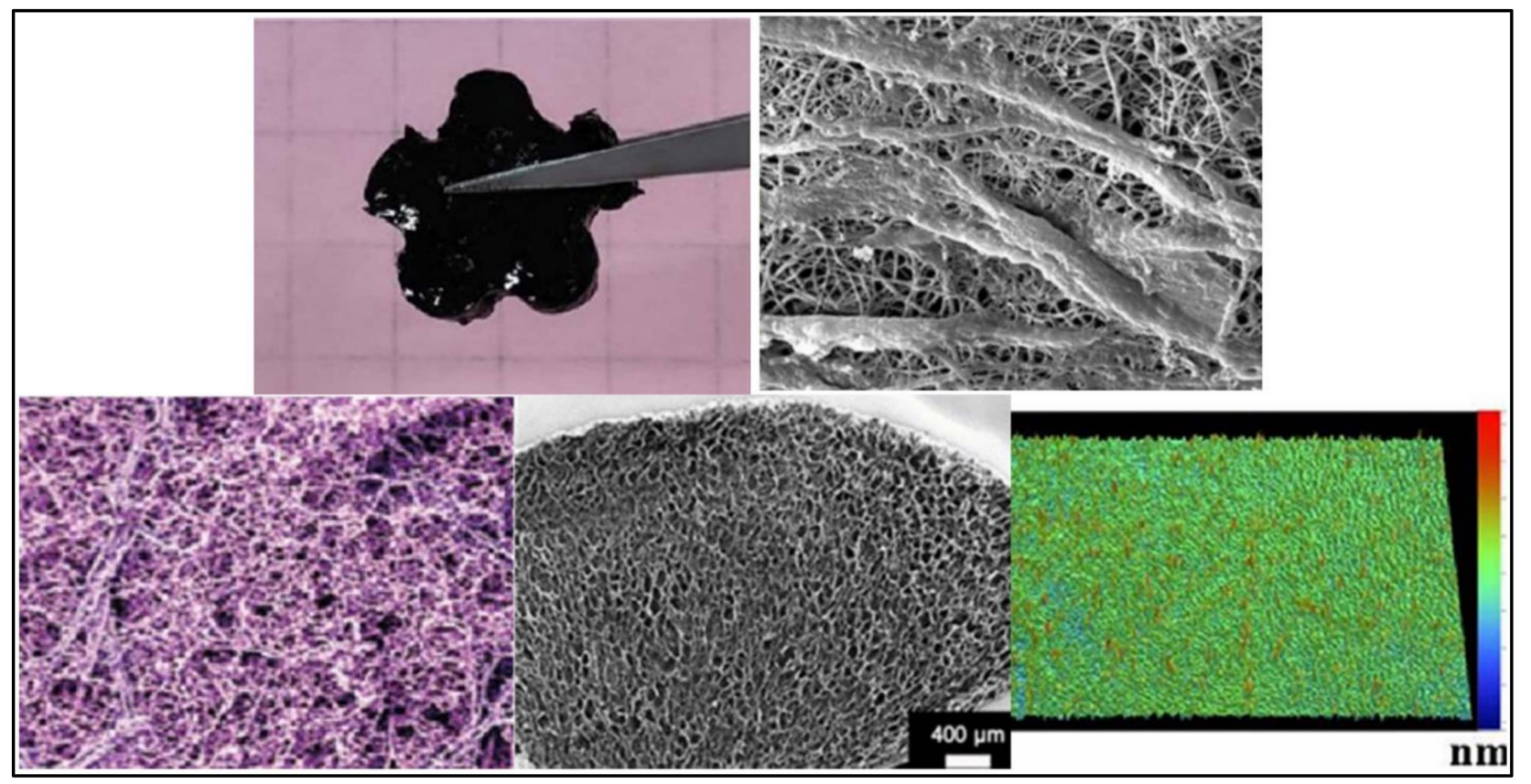

Figure 4. Images of scaffold structures: porous hydrogel, nanofibrous, porous hydrogel scaffold, porous sponge scaffold, and hydrogel patch scaffold $[18,29,30,34,39]$.

Recently, the antibacterial, mechanical, and physical properties of a collagen-chitosan sponge scaffold, constructed from aquatic sources, were studied [56]. The researcher applied the lyophilisation technique $\left(-50{ }^{\circ} \mathrm{C}, 0.5 \mathrm{Mbar}\right.$ vacuum pressure) to acquire a highly porous-structured scaffold. Furthermore, they added an alginate compound to the scaffold to improve its mechanical properties. The sponge scaffold's porosity was in the range of $88-95 \%$, with the addition of biopolymers, such as alginate and chitosan, onto the collagen [56]. Moreover, injectable-electroconductive hydrogels have the potential to improve cell survival, which could be translated into a novel treatment protocol $[29,42,57]$, while minimising the need for invasive surgery. Additionally, the incorporation of electroconductive nanomaterials in hydrogels may influence their bulk electrical properties and topography, which can also affect the retention and biology of living cells. For instance, the application of CPs, such as PEDOT: PSS, in hydrogel scaffolds promotes the rhythmic beating in a neonatal rat cellular matrix $[34,58]$. The use of PEDOT in chitosan-based gels also resulted in an excellent regenerative capacity [43]. 
Table 1. Summary of scaffold fabrication techniques.

\begin{tabular}{|c|c|c|c|}
\hline Fabrication Method & Scaffold Structure & Major Findings & Reference \\
\hline Ionic grafting technique & $\begin{array}{l}\text { Interconnected } \\
\text { porous-hydrogels }\end{array}$ & $\begin{array}{l}\text { Formation of conductive and } \\
\text { self-healable hydrogels. }\end{array}$ & [29] \\
\hline Lyophilization technique & Sponge scaffold & $\begin{array}{l}\text { The mechanical properties of collagen } \\
\text { sponges were improved with the addition of } \\
\text { alginate. Future research can confirm its } \\
\text { potency in the healing of skin ulcers. }\end{array}$ & [33] \\
\hline Drop-casting technique & Hydrogel-patch scaffold & Stable and conductive scaffold patch. & [18] \\
\hline $\begin{array}{l}\text { Chemical mixing-a } \\
\text { filtered technique }\end{array}$ & Hydrogel scaffold & $\begin{array}{l}\text { Electroactive hydrogels with advantageous } \\
\text { characteristics: covalently crosslinked porous } \\
\text { 3D scaffolds with notable swelling ratio, } \\
\text { excellent mechanical properties, } \\
\text { electroactivity in physiological conditions } \\
\text { and cell proliferation and differentiation. }\end{array}$ & [56] \\
\hline Lyophilization technique & Porous-sponge scaffold & $\begin{array}{l}\text { Scaffold biomimicry was enhanced with the } \\
\text { addition of collagen. Collagen increases } \\
\text { electrochemical impedance responses. } \\
\text { Controlling scaffold's mechanical properties } \\
\text { is highly beneficial for understanding the } \\
\text { factors influencing cell behaviour in 3D } \\
\text { scaffold structures. }\end{array}$ & [30] \\
\hline Electrospinning technique & $\begin{array}{l}\text { Nanofibrous } \\
\text { mat-structured scaffold }\end{array}$ & $\begin{array}{l}\text { The application of PEDOT: PSS with special } \\
\text { electrical and mechanical properties as a } \\
\text { scaffold is recommended for cardiac TE. }\end{array}$ & [25] \\
\hline
\end{tabular}

Iandolo et al. (2020) studied biomimetic scaffolds that supported neural crest-derived stem cell osteogenic differentiation [30]. The highly porous scaffolds were prepared by combining PEDOT: PSS with collagen type I, using the ice-templated technique. Collagen type I and PEDOT: PSS were blended in an ultrasonic bath to ensure the mixture's homogeneity. Next, the mixture was poured into a specific mould with the desired shape, followed by freeze-drying and thermal treatment. (3-glycidyloxypropyl) trimethoxysilane (GOPS) was used as the crosslinker to enhance the mechanical properties of the scaffolds. Heat treatment was performed to reticulate the crosslink [30]. The outcome of this study was a porous scaffold with the desired geometry. The ice templating process was necessary to create highly porous scaffolds that were compatible with cell infiltration and proliferation.

Another technique that is used to fabricate conductive scaffolds is electrospinning. Abedi et al. (2019) studied the fabrication and characterisation of conductive nanofibrous chitosan/PEDOT: PSS for cardiac TE. PEDOT: PSS was paired with chitosan due to its chemical and thermal stability. The combination promoted the scaffold's electrical properties, mirroring the myocardium ECM. A double nozzle electrospinning apparatus was used to form a fibrous mat structure of a conductive scaffold. The scaffold was then crosslinked using the glutaraldehyde solution vapor technique [25]. They discovered that the addition of PEDOT: PSS into chitosan/polyvinyl alcohol (PVA) increased the scaffold's conductivity. The electrospinning and crosslinking of the fibrous mat scaffold increased its mechanical strength. The presence of hydrogenic bonds, between $\mathrm{OH}$ groups in PVA and chitosan, and $\mathrm{SO}^{-3}$ groups in PSS in the CPs' dispersion, also contributed to its higher mechanical strength. Interestingly, the fibrous mat of the chitosan/PVA/PEDOT: PSS scaffold promoted the attachment and proliferation of cells.

When fabricating and designing a suitable and safe TE product, scaffolds should be able to biodegrade and should support cellular growth in vitro and in vivo. However, other aspects, such as attachment, migration, and cell proliferation, must also be taken into consideration. These aspects are highly dependent on the scaffold's surface properties and 
its interaction with transmembrane proteins. Low-risk tissue regeneration processes can be achieved with advanced scaffold technology.

\section{The Crosslinking Process in Fabricating Conductive-Polymeric Scaffolds}

During the fabrication of polymeric scaffolds, the crosslinking process is adopted to chemically bind the molecules within the scaffold's structure. This, in turn, significantly influences their mechanical properties. For example, the crosslinking process upon a nanofibrous-structured scaffold causes the fibres to attach and stack between each other, resulting in better resistance performance to the application of shearing forces. The crosslinker can be divided into three types: chemical crosslinker, biophysical crosslinker, and enzymatic crosslinker. Adding crosslinkers can enhance their mechanical properties; however, this can affect their physical condition, causing the scaffolds to become contracted or shrunk. However, in the presence of dehydrothermal (DHT), crosslinking can prevent scaffold contraction, thus making scaffolds more stable for a long period of time. Meanwhile, crosslinking with ultraviolet (UV) light can enhance the scaffold's stability in an aqueous environment, and does not cause any physical changes to the scaffolds [58-60]. This may be due to the fact that the UV light crosslinking process does not take place chemically, and interacts with the compound that is present in the scaffolds. UV crosslinking hardened the liquid polymeric material to be more stable and to possess a rigid shape, with no heat exposure exerted on the material [61]. In addition, crosslinking can also avoid the premature dissolution of the scaffold at the normal body temperature [62]. Figure 5 shows an illustration of the mechanism of the scaffold's crosslinking processes. Extensive research has been performed to develop biomedical scaffolds that meet the criteria of cost-effective fabrication, ease of customisation, and safe application in clinical settings, particularly in the areas of infection treatment and drug delivery $[38,63]$.

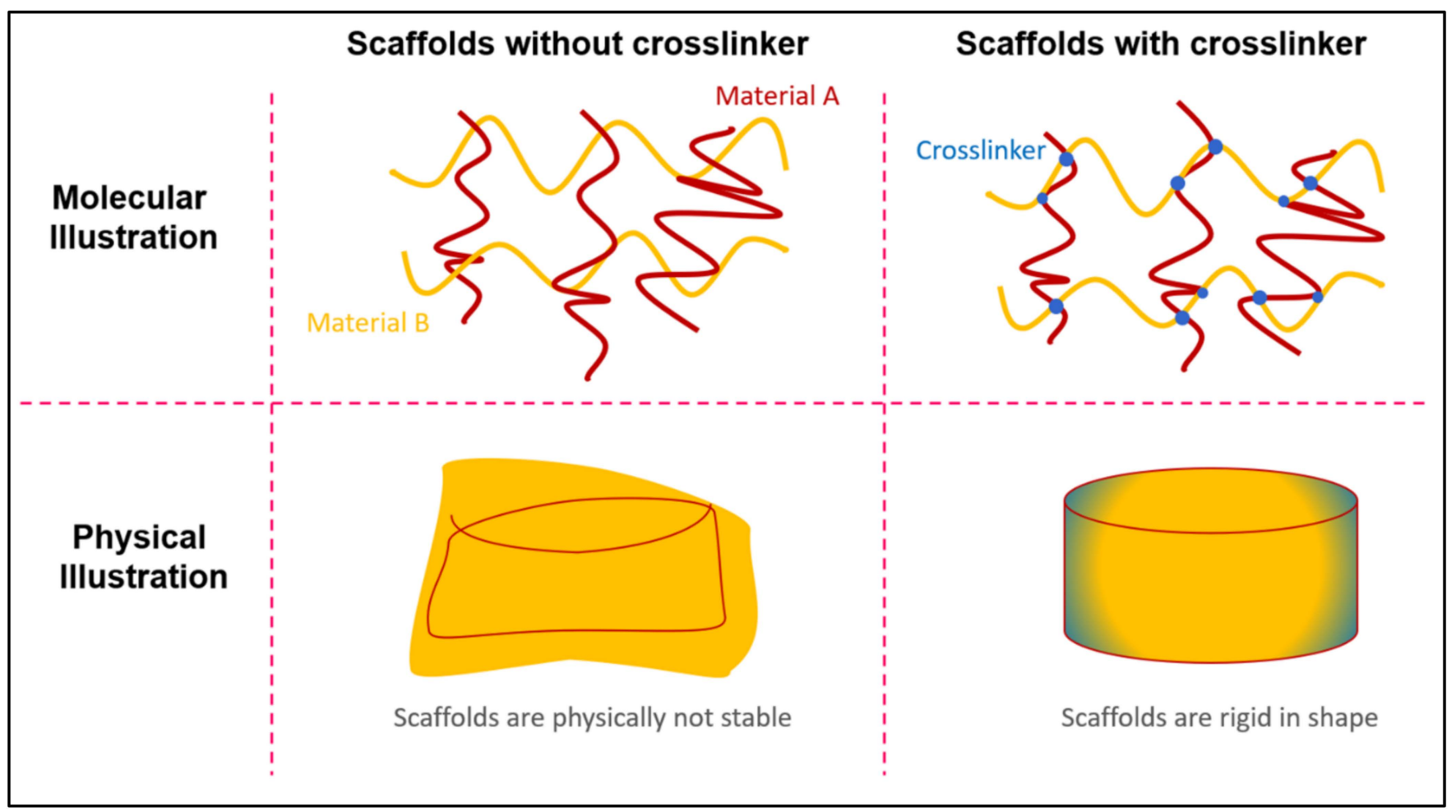

Figure 5. Illustration of the enhancement of a scaffold's mechanical properties by employing the crosslinking processes.

The intermolecular crosslinking of collagen-based scaffolds, either through chemical or physical methods, can modify their mechanical properties [12,56]. However, some wellknown crosslinking agents, such as glutaraldehyde (GTA), glyoxal, and glycol diglycidyl ether, are toxic [64,65]. According to Hua et al. (2020), sodium tripolyphosphate (TPP) 
is a safe crosslinker for collagen and chitosan, with excellent biocompatibility [66]. A comparative study of crosslinkers reported that genipin (GP) and TPP had better biocompatibility, compared to GTA, towards the collagen/chitosan scaffold. Nonetheless, TPP was recommended as the most suitable crosslinking agent for myocardial TE [67]. In their study, collagen and chitosan were dissolved in a $1 \%(v / v)$ acetic acid solution at room temperature. After fabrication was carried out using the lyophilisation method $\left(-20^{\circ} \mathrm{C}\right.$ for $\left.48 \mathrm{~h}\right)$, a $1: 1$ ratio of a lyophilised collagen/chitosan scaffold was crosslinked. In the case of collagen, crosslinking could be achieved through the formation of an amide, from the activation of the carboxylic group with the amine. In comparison, 1-(3-dimethyl aminopropyl)-3-ethyl carbodiimide hydrochloride and $\mathrm{N}$-hydroxysuccinimide were employed as crosslinkers to strengthen the covalent attachment between the carbonyl group of gelatine and the amino group of chitosan in the porous PEDOT/Chitosan/Gel scaffolds [41].

Interestingly, a study focusing on poly(vinyl) alcohol-gellan gum-based nanofiber proved that a scaffold's degradation rate could be controlled by various crosslinking agents [38]. In addition, for electroconductive hydrogels (EH), there are several types of suitable crosslinking processes, such as physical crosslinking, covalent crosslinking, and supramolecular crosslinking. However, each of these crosslinking techniques may affect the biodegradability of the EH scaffold. The density and concentration of the crosslinker can alter the properties of the scaffolds, including their water content, mesh size, porosity, diffusivity, and mechanical characteristics [60,68-70]. Overall, the use of crosslinkers could physically change the properties of scaffolds, which can affect the biodegradability of the scaffolds. This idea warrants further investigation, focusing on the execution of scaffolds ${ }^{\prime}$ optimum degradation rates by varying the concentration of any crosslinker.

\section{Physical Properties of Conductive-Polymeric Scaffolds}

No single polymeric system can be considered the ideal biomaterial for all medical applications, due to the complexity of the human body and the scope of applications that polymeric biomaterials are currently utilized for. Thus, a mixture of natural and synthetic polymers can overcome the limitations of a monocomponent system [12]. Theoretically, a composite scaffold that is composed of more than two sub-materials exhibits a greater characteristic value, due to the combination of materials that hold some desired properties. Due to the various needs of scaffolds, composite materials with excellent properties are commonplace in TE [71]. For example, Lari et al. (2016) fabricated nanohydroxyapatite/chitosan (nHAp/CS) composite scaffolds that were embedded with PEDOT: PSS through a lyophilization technique. They found that nHAp and PEDOT: PSS were homogeneously dispersed in the chitosan matrix. The CS/nHAp/PEDOT: PSS scaffolds exhibited a high cell attachment rate, due to their surface roughness. The electrical conductivity that was recorded for the CS/nHAp/PEDOT: PSS sample was $9.72 \pm 0.78 \mu \mathrm{S} / \mathrm{m}$. They also found that both the compressive modulus and the yield strength of the chitosan increased to $0.5-1.0 \mathrm{MPa}$ and 5-5.5 $\mathrm{MPa}$, respectively, with the addition of nHAp and PEDOT: PSS. Unfortunately, the CS/nHAp/PEDOT: PSS had poor biodegradability, due to the strong bonding between PEDOT: PSS and the rest of the substrate chains [26]. Meanwhile, Iandolo et al. (2020) prepared highly porous biomimetic scaffolds by combining the PEDOT: PSS with collagen type I (the most abundant protein in bone) for inactive support. However, aggregation took place when collagen was a part of the mixture, due to the interaction between the positively charged protein chains and the negatively charged polystyrene sulfonic acid groups, which caused the restructuring of the CPs. Unfortunately, this process contributed to the de-doping of the conductive PEDOT segments.

Abedi et al. (2019) demonstrated that the addition of PEDOT: PSS in chitosan scaffolds could improve their biocompatibility, cell viability, and mechanical and electrical properties. In their study, the electrical conductivity, elongation at break (\%), ultimate strength, and toughness of CS/PVA/PEDOT: PSS scaffolds were recorded at $7.63 \times 10^{-3} \mathrm{~S} / \mathrm{m}, 5.6 \pm 0.3 \%$, $18.78 \pm 0.95 \mathrm{MPa}$, and $48.87 \times 10^{6} \mathrm{~J} \mathrm{~m}^{-3}$, respectively. They also discovered that the attachment length of the cells increased as the nanofiber diameter was decreased to $40 \mathrm{~nm}$. 
Further shrinkage of the fibre diameter to less than $40 \mathrm{~nm}$ affected the attachment of cells. However, the addition of PEDOT: PSS can be toxic, depending on the weight composition. The addition of more than $0.6 \mathrm{wt}$.\% PEDOT: PSS in gelatine scaffolds causes toxicity in stem cells; this means that the gelatine amount must be lower than $0.6 \mathrm{wt} \%$ in a single scaffold composition [25]. Overall, previous studies established that PEDOT: PSS, which is favourable for cell proliferation, can be the predecessor for a highly biomimetic, electroactive scaffold for stem cell expansion and differentiation [30].

It is essential to establish a link between materials degradation in vitro and mechanomorphological characteristics, since biodegradation can negatively affect the mechanical and structural integrity of the scaffolds. Biodegradation is manifested by material loss in grafted scaffold structures because of ageing in the PBS medium. The biodegradation rate of a scaffold can be determined by the calculation of weight loss in PBS conditions. A higher percentage of mass loss in the scaffolds can be attributed to the high surface area and porosity of scaffolds [72]. For example, Zhang et al. (2008) investigated the in vitro biodegradation of an electrospun tubular protein scaffold, by immersing the scaffold in a PBS condition $(\mathrm{pH}=7.3)$ for various timeframes. This was then followed by determining the scaffolds' weight loss percentage. Ideally, the degradation rate of the scaffold should be similar to the rate of new tissue formation. The mechanical and electrical properties of various scaffolds are summarised in Table 2. In addition, the conductivity of the fabricated scaffold should refer to the sheet conductivity of the material, which is different from the commonly evaluated electrochemical impedance responses of the coated electrodes.

Table 2. Mechanical and electrical properties of conductive-based scaffold materials.

\begin{tabular}{|c|c|c|c|c|}
\hline Scaffold Material & Conductivity (S/m) & $\begin{array}{c}\text { Mechanical Strength } \\
(\mathrm{MPa})\end{array}$ & Major Findings & References \\
\hline $\begin{array}{c}\mathrm{CS} / \mathrm{nHAp} / \mathrm{PEDOT} \\
\text { sponges }\end{array}$ & $9.72 \pm 0.78 \times 10^{-6}$ & $5.0-5.5$ & $\begin{array}{l}\text { PEDOT: PSS/nHAp/CS is a } \\
\text { promising scaffold, due to its } \\
\text { porosity, microstructure, } \\
\text { conductivity, and cell response. }\end{array}$ & [26] \\
\hline Chitosan/aniline Patch & - & $6.73-1.14$ & $\begin{array}{l}\text { A better understanding of the } \\
\text { role of conductive materials in } \\
\text { electro-responsive tissues in ex } \\
\text { vivo and in vivo models can be } \\
\text { achieved by applying } \\
\text { bioelectronic devices onto the } \\
\text { biotic-abiotic interface. }\end{array}$ & [18] \\
\hline $\begin{array}{l}\text { CS/PEDOT: PSS } \\
\text { nanofibrous }\end{array}$ & $\begin{array}{c}\left(1.5 \times 10^{-3}-7.63 \times\right. \\
\left.10^{-3}\right)\end{array}$ & $13.07 \pm 1.09-18.78 \pm 0.95$ & $\begin{array}{l}\text { Scaffolds with PEDOT: PSS } \\
\text { showed greater cell support } \\
\text { without any cell toxicity. The } \\
\text { smaller fibre diameter of the } \\
\text { fibrous mat structure can aid } \\
\text { cell attachment. }\end{array}$ & [25] \\
\hline $\begin{array}{c}8 \% \\
\text { PEDOT-HA/Cs/Gel } \\
\text { hydrogel }\end{array}$ & $\left(3.16 \times 10^{-3}\right)$ & $\begin{array}{l}47.3 \pm 0.3 \times 10^{-3} \\
\quad(\text { compressive })\end{array}$ & $\begin{array}{l}\text { An } 8 \% \text { PEDOT-HA/Cs } / \mathrm{Gel} \\
\text { hydrated scaffold, with the } \\
\text { compressive modulus of } \\
47.3 \pm 0.3 \times 10^{-3} \mathrm{MPa} \text {, is a } \\
\text { viable candidate for brain tissue } \\
\text { in nerve TE. }\end{array}$ & [9] \\
\hline $\begin{array}{c}\text { Conductive PEDOT } \\
\text { layer assembled } \\
\text { Cs/Gel }\end{array}$ & $\begin{array}{c}\left(6.51 \times 10^{-3}\right) \text {-6th } \\
\text { week } \\
\left(1.82 \times 10^{-3}\right) \text {-8th } \\
\text { week }\end{array}$ & - & $\begin{array}{l}\text { Although the conductivity of } \\
\text { scaffolds depreciated with } \\
\text { progressing biodegradation, they } \\
\text { still met the electrical } \\
\text { conductivity requirements for } \\
\text { electrical stimulation in neural } \\
\text { TE application. }\end{array}$ & [10] \\
\hline
\end{tabular}




\section{Biodegradation Mechanisms of Polymeric-Based Scaffolds}

Recent advances in biodegradable biomaterial synthesis have been directed toward developing and synthesizing polymers with properties that are tailored for specific biomedical applications. Understanding the biodegradation mechanism of scaffolds in the physiological environment is necessary to optimise their functionality [73]. There are two types of biodegradation process: surface degradation and bulk degradation. As illustrated in Figure 6, the type of biodegradation depends upon the diffusivity of water inside the matrix, the degradation rate of the polymer's functional groups, and the size of the matrix. Polymeric scaffolds that experience surface degradation will preserve their bulky structures, even when their overall size is reduced. The bulk degradation of polymeric material will demolish the scaffold's internal structure and reduce its molecular mass [74].

Biodegradable scaffold materials will experience a gradual breakdown that is dependent on biological, chemical, and biophysical aspects and factors. The four types of polymeric in vivo degradation mechanisms are hydrolytic, oxidation, stimuli-associated, and enzymatic $[6,27,75,76]$, as summarized in Figure 7 . The biodegradation of polymeric biomaterials such as scaffolds involves a hydrolysis process that is initiated by water molecules and the disintegration of sensitive bonds in the polymer by enzymes. These events cause the erosion of the polymer. The biodegradation rate depends upon the physiological environment and the intrinsic properties of the scaffolds, as follows: (1) the chemical structure, (2) the presence of hydrolytically unstable bonds, (3) the level of hydrophilicity and hydrophobicity, (4) the crystalline morphology, (5) the glass transition temperature, (6) the copolymer ratio, (7) molecular weight, (8) tacticity, (9) loading direction, (10) $\mathrm{pH}$, and (11) the treatment processes that are involved during scaffold fabrication, such as crosslinking process $[69,77]$.

\section{Surface Degradation}
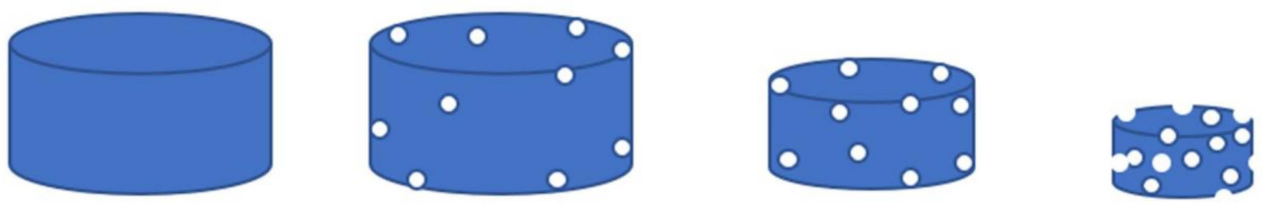

Overall size is reduced

Bulky structure is maintained

\section{Bulk Degradation}
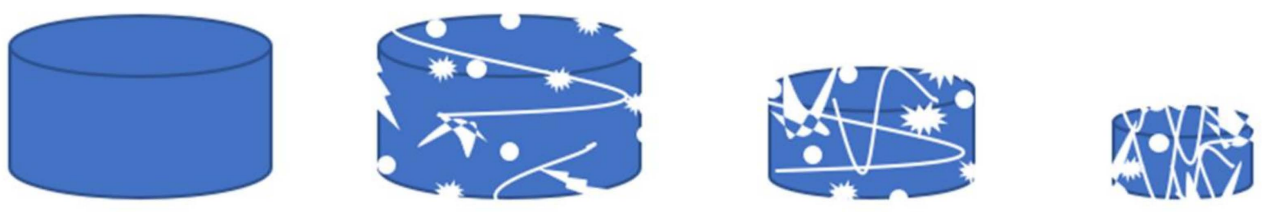

Molecuiar mass is reduced

Internal structure is demolished

Figure 6. Illustrations of the surface and bulk degradation process. 


\section{Degradation Mechanism}

Oxidation Mechanism

(Yang et al., 2019)
Hydrolytic Degradation

(Tamariz and Rios-

Ramrez, 2013)
Enzymatic Degradation

(Woodard and Grunlan, 2018)
Stimuli-Associated

Degradation

(Yang et al., 2019)

Figure 7. Different types of degradation mechanisms in physiological condition.

The hydrolytic degradation of polymers entails the collapse of chemical bonds in the polymer backbone by water molecules. Acids, bases, or salts catalyse the degradation to form oligomers and monomers. This form of degradation significantly reduces the molecular weight of the polymer. A previous study reported that the addition of PPy causes the polymer chains in scaffolds to aggregate and resist water diffusion, which slows down the degradation rate. This is due to the increasing number of hydrophobic bonds that are present after the blending of PPy with the PCL-CS mixture [78]. Figure 8 is an example that illustrates the hydrolytic degradation mechanism of PLA scaffolds. Mild hydrolysis results in the slight degradation of the polymer's surface, revealing the surface carboxyl and hydroxyl groups. Carboxyl may be present in several forms, including the carboxylate ion, carboxylic acid, and carboxyl salt [79].

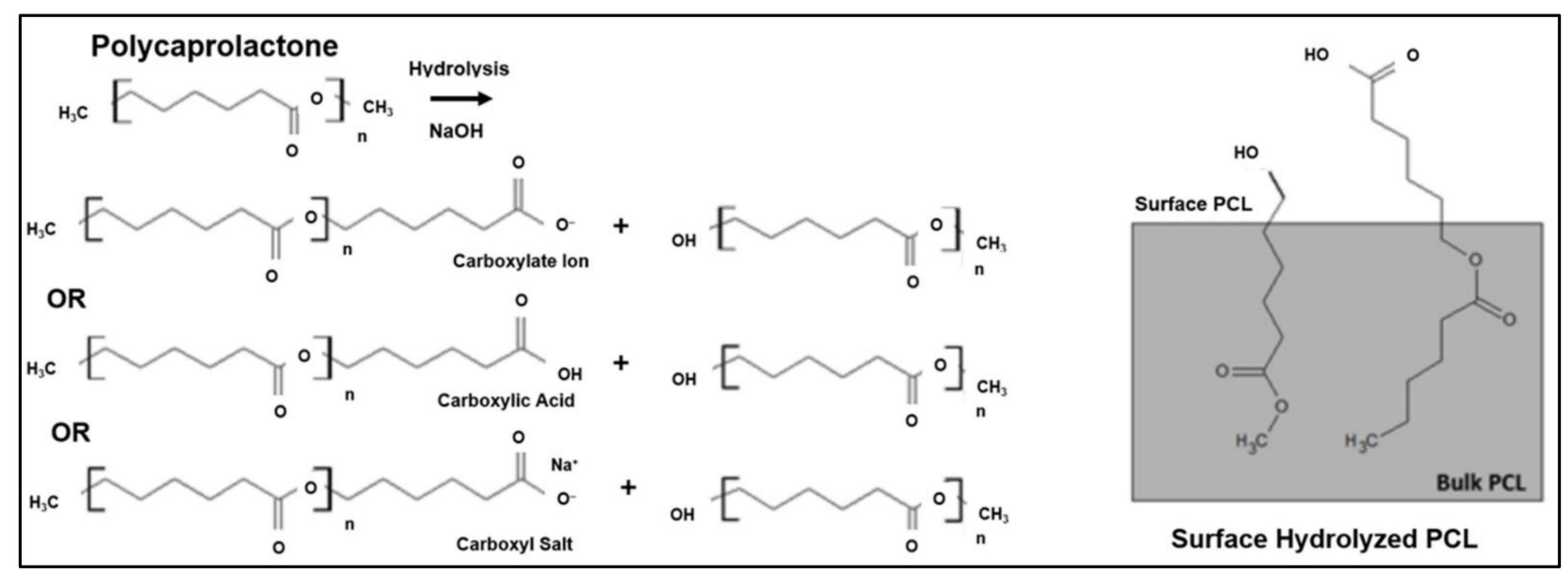

Figure 8. The hydrolytic degradation mechanism of PCL scaffolds [79].

The degradation mechanism process can also be mediated by biological agents, such as enzymes, that partake in tissue remodelling. Polymeric scaffolds are also vulnerable to oxidation mechanisms. When scaffolds are exposed to body fluids and tissues, the host's immune cells will initiate inflammatory responses. This situation can cause the release of highly reactive oxygenic molecules, such as hydrogen peroxide $\left(\mathrm{H}_{2} \mathrm{O}_{2}\right)$, superoxide $\left(\mathrm{O}_{2}-\right)$, nitric oxide $(\mathrm{NO})$, and hypochlorous acid $(\mathrm{HOCl})$. These molecules accelerate polymer chain scission and the degradation of scaffolds. Figure 9 shows an example of the oxidative degradation of poly (urethane) derivatives by hydrogen peroxide compound, including (A) poly(ether urethanes), (B) poly(carbonate urethanes), and (C) aromatic polyurethanes, which produce glycol ether radicals as by-products. 


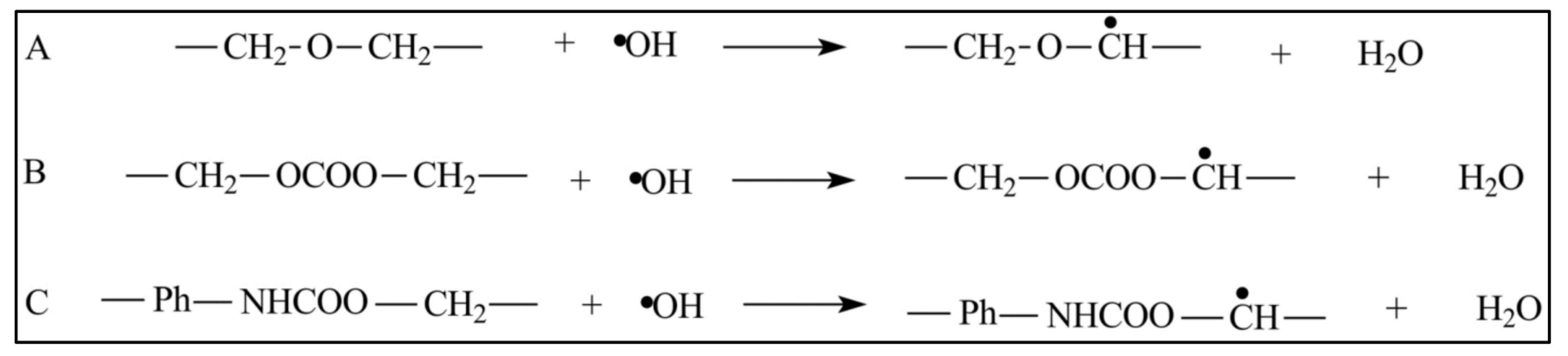

Figure 9. A mechanism of oxidative degradation by $\mathrm{H}_{2} \mathrm{O}_{2}$ in poly(ether urethanes) (A), poly(carbonate urethanes) (B), and aromatic polyurethanes (C) [80].

The degradation mechanism process can also be mediated by biological agents, such as enzymes, that partake in tissue remodelling [73]. Figure 10 shows an example of the enzymatic degradation mechanism of methyl methacrylate-poly 3-(trimethoxysilyl) propyl methacrylate (MMA-TMSPMA) star polymers that are synthesised with the arms of three different architectures (random, inner, and outer), crosslinked with a dimethacryloyl peptide (MaCh-peptide) core, and cleaved with collagenase activity [81]. The enzymatic mechanism often proceeds, concurrently, with hydrolytic degradation. The presence of hydrolases enzymes, such as proteases, esterases, glycosidases, and phosphatases, catalyses the hydrolysis reaction of biomaterial disintegration [27]. The interaction between the enzymes and the polymeric chains begins with the diffusion of specific enzymes on the polymer's solid surface. This diffusion is followed by the enzyme-substrate complex formation, whereby the substrate causes a conformational or shape change of the enzymesubstrate complex. Catalysis of the hydrolysis reaction occurs, and the soluble by-products diffuse into body fluids [6].

Additionally, Figure 11 shows examples of the stimuli that are associated with degradation mechanisms; a pH-sensitive drug-gold nanoparticle system for tumour chemotherapy, and surface-enhanced Raman scattering (SERS) imaging [82]. This concept can be applied to scaffold degradation mechanisms with the use of doxorubicin drugs as fillers for a specific treatment. According to Yang et al. (2019), a stimuli-associated degradation mechanism that encourages scaffold swelling normally manifests in sol-gel degradation behaviour. In this case, the degradation process occurs by allowing the scaffold network structure to be cleaved by external triggers: $\mathrm{pH}$-responsive, light-responsive and redox-responsive [8]. A pH-responsive smart hydrogel offers targeted and controlled release behaviour to wounds, while its network architecture remains intact, with slower degradation in normal tissues. A photo-responsive hydrogel goes through light-mediated degradation, while redox-responsive hydrogels react to internal and external oxidative and reductive stimuli.

The scaffold degradation rate should be on par with the tissue ingrowth to maximise healing or to deliver healable drugs. Generally, the degradation of polymers in physiological conditions is caused by a molecular chain scission that is initiated by hydrolysis (anhydride, ortho-ester, ester, urea, urethane/carbonate, and amide bonds) or enzymecatalysed hydrolysis. A number of degradable polymeric scaffolds contain labile bonds that tend to hydrolyse. Additionally, these bonds are too stable under physiological conditions. Thus, they require an enzymatic catalyst to encourage degradation [70]. There are several non-invasive techniques to monitor in vivo scaffold degradation. Electron paramagnetic resonance (EPR) is an efficient and accurate technique to investigate radical and oxidative stresses [83]. Ultrasound elasticity imaging (UEI) can be used to characterise the structural, functional, and compositional changes of biodegradable scaffolds via phase-sensitive speckle tracking $[84,85]$. Several non-invasive and non-destructive techniques to investigate parameters such as a scaffold's $\mathrm{pH}$ value, distribution, and cell viability are: (i) confocal laser scanning microscopy (CLSM); (ii) nuclear magnetic resonance (NMR); (iii) optical coherence microscopy (OCM); (iv) optical coherence tomography (OCT). OCT can be used in 
tandem with various light sources, such as near-infrared fluorescence (NIR) [86,87]. Zhang et al. (2020) innovated a multifunctional hydrogel system with tetraphenylethene (TPE), that has similar traits to aggregation-induced emission (AIE) nanoparticles, to monitor the degradation of hydrogel scaffolds in physiological conditions [88,89].

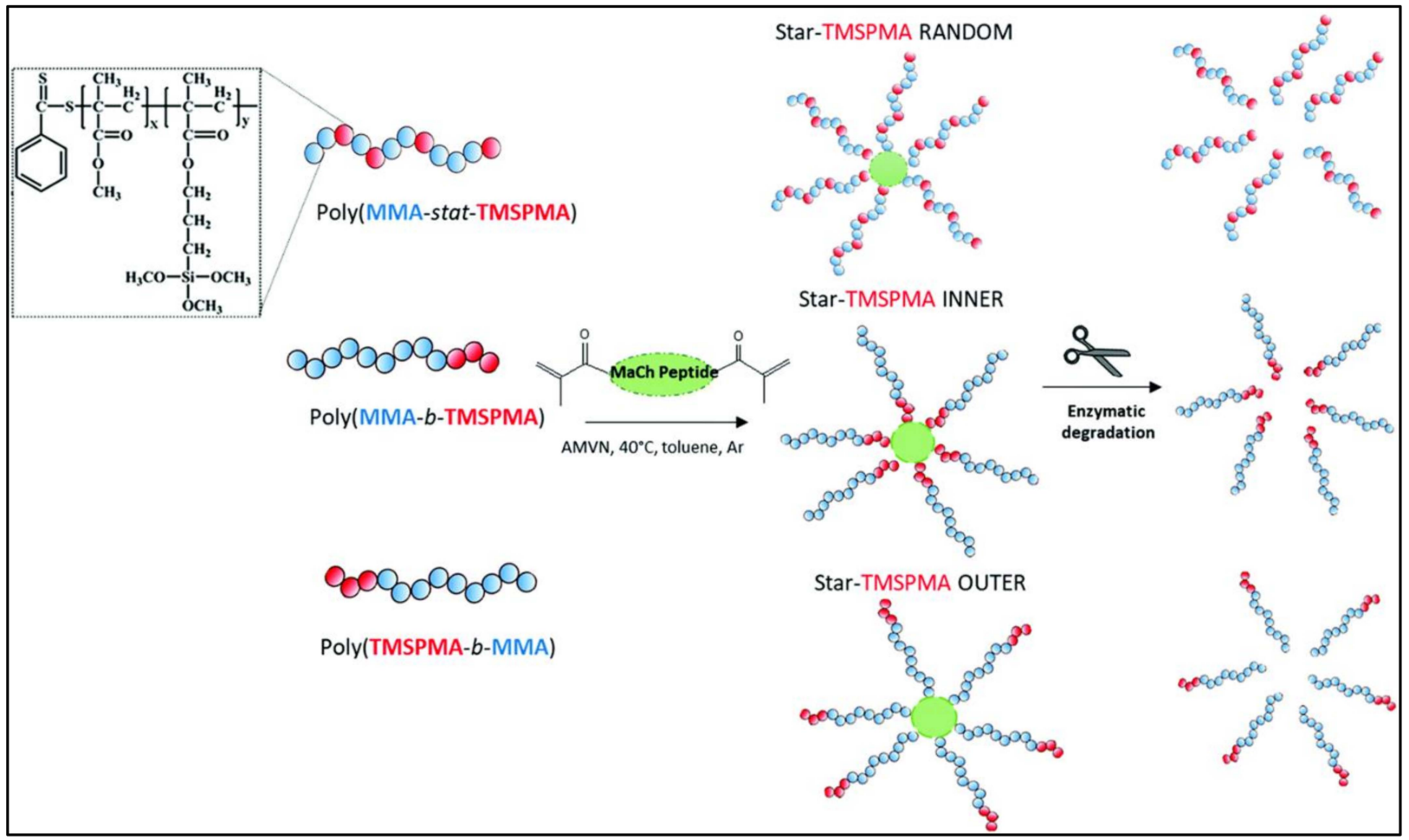

Figure 10. Illustration of the enzymatic degradation process [81].

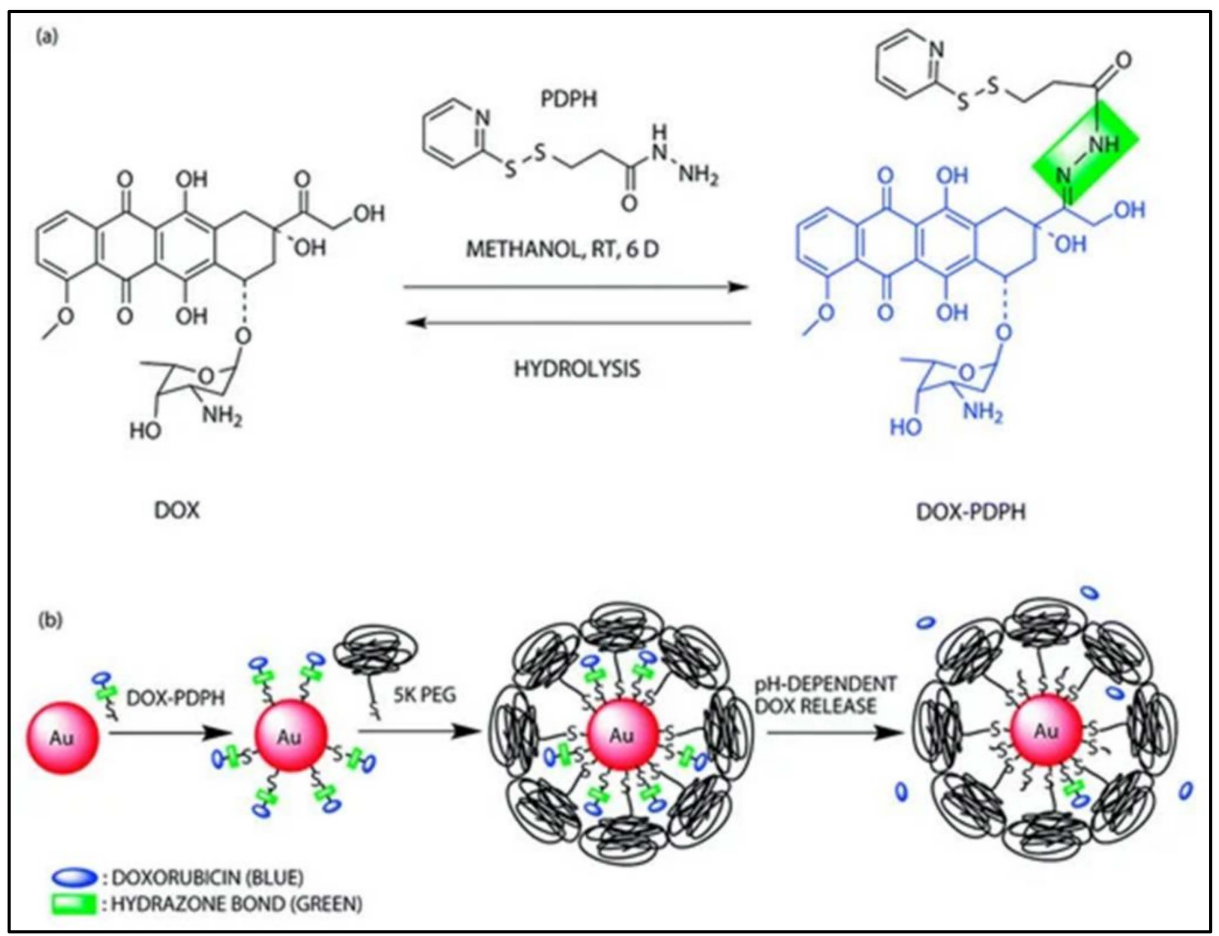

Figure 11. A pH-sensitive drug-gold nanoparticle system: (a) chemical synthesis of the doxorubicinhydrazone linker conjugate (dox-PDPH); (b) schematic illustration of the synthesis of the multifunctional drug delivery system and its $\mathrm{pH}$-dependent doxorubicin release [82]. 


\section{Immunogenic Effects on the Biodegradation Behaviour of Scaffolds}

Immunogenicity is a biological response to the presence of non-compatible foreign substances or living organisms in the body. This reaction can cause complications for one's health. Therefore, biocompatible scaffolds are imperative to circumvent immunogenic effects. The by-products of degradation, such as monomers, oligomers, and polymer fragments, should be biocompatible with the human body, and should be able to pass through filtering organs without causing any complications. Scaffold materials with a low degradation rate might lead to transplant failure, due to negative immune responses. Woodard and Grunlan (2018) [75] underlined the scaffold's dimensions as a factor that influences degradation. This idea was also presented in another study [74].

Figure 12 illustrates how different biodegradation rate trends are capable of tuning the immunogenicity of scaffolds. A poor degradation rate of a non-compatible scaffold will inhibit tissue regeneration, since the scaffold will continuously trigger immune reactions. However, incompatible scaffolds with high degradation rates could compromise tissue regeneration rates, due to the absence of cellular support. Altering the material degradation rate seems to be a promising means of optimising the scaffold's biocompatibility. Natural polymers often exhibit better biocompatibility and biodegradability. However, the degradation of synthetic polymers can be tailored accordingly. Acidic by-products, which are hydrolytically produced from polyester scaffold degradation, may also cause physiological inflammatory responses [75]. In some cases, a low $\mathrm{pH}$ environment can unnecessarily accelerate the scission of scaffolds. Therefore, biodegradable polyester for physiological purposes can be optimised by introducing basic salts into the polyester, such as calcium carbonate, sodium bicarbonate, and calcium hydroxyapatite [75]. The use of biodegradable natural polymers, such as collagen, was suggested, according to the presence of collagenase as a physiological enzyme [90]. The presence of natural polymers in scaffolds only triggers mild biological responses, and this can prevent severe immunogenicity side effects.

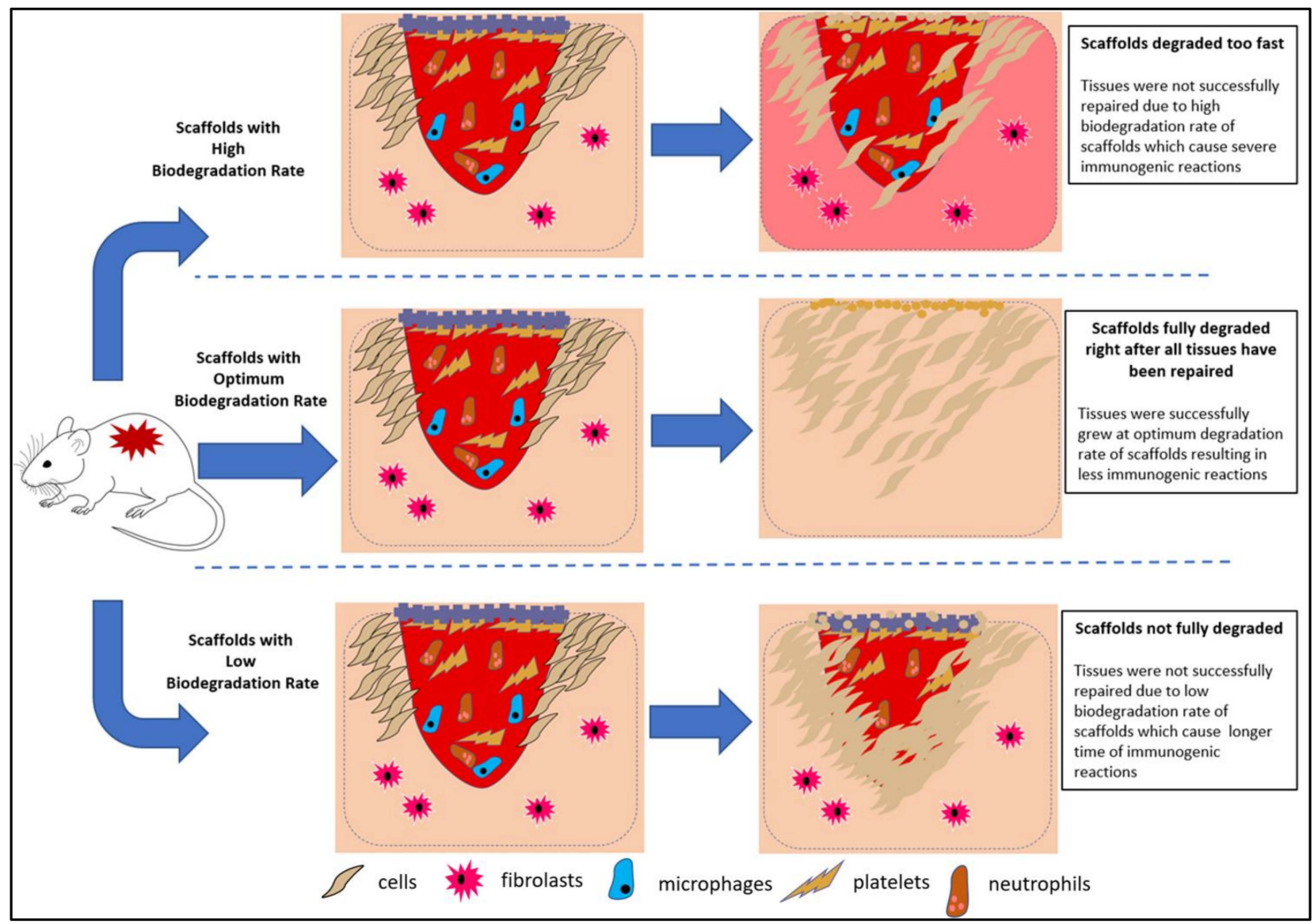

Figure 12. Illustration of the different immunogenic responses towards the specific biodegradation trends of scaffolds. 


\section{Common Conductive and Biodegradable Scaffolds}

\subsection{PEDOT-Based Scaffolds}

\subsubsection{Characteristics of PEDOT-Based Scaffolds}

To utilize CPs for developing and synthesizing scaffolds with properties that are tailored for use in tissue engineering, the suitable conductive and hybrid systems of biocompatible scaffolds must be discussed. Extensive research is ongoing to optimise the stability of scaffolds, by incorporating composite materials to overcome the problems with tissues $[18,38,58,68,91]$. The scaffold materials must fulfil the criteria of convenient sterilisation, biocompatibility, and non-toxicity [92]. The seamless electrical communication among cells, and the optimised growth of cells, can be achieved by exploiting scaffolds with sufficient electrical conductivity. Recently, the focus of scaffold-based TE is on the enhancement of bone healing via electrical stimuli with CPs [40]. The addition of modified electroactive oligomers can control the biodegradability of CPs. These grafted copolymers are connected via degradable ester linkages, and are highly sought after in biomedical applications that employ pyrrole, aniline, or thiophene groups [23]. Unfortunately, electroactive aniline-based oligomers are toxic to human bodies. In response to this observation, Mawad et al. (2016) proposed 3,4-ethylene dioxythiophene (EDOT)-based oligomers as an alternative to replace aniline-based oligomers, to minimise the biomaterial's toxicity [54].

PEDOT can be chemically tuned to alter the mechanical and electrical properties of scaffolds. This tuning can promote the covalent attachment between biomolecules and scaffolds to become biocompatible [93]. In addition, conductive scaffolds are conductive for the differentiation and proliferation of electrically stimulated responsive cells [28]. PEDOT: PSS is a common biocompatible CP behind conductive scaffolds. Figure 13 shows the chemical structure of PEDOT: PSS. This copolymer has a moderate band gap and excellent stability [25]. For example, the addition of PEDOT: PSS in a chitosan-based electrospun scaffold not only enhances the scaffold's mechanical and electrical conductivity, but also improves its biocompatibility and cell viability [24]. The findings regarding the biodegradability of various scaffolds including conductive scaffolds from previous research are summarised in Table 3. Predominant crosslinking in scaffold fabrication (as discussed in the Crosslinking Process section in Fabricating Conductive-Polymeric Scaffolds (Section 3)), increases the mechanical properties and stability of the scaffold at the possible expense of the scaffold's biodegradability.

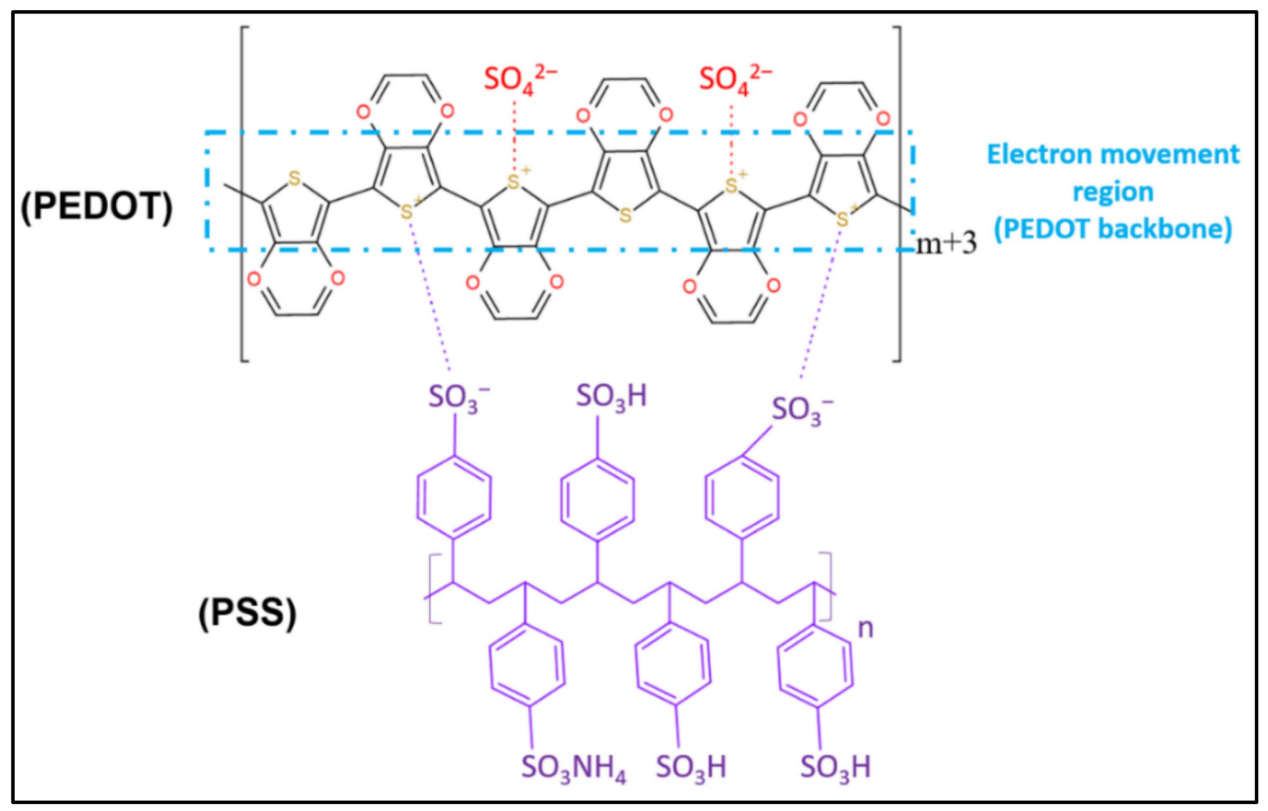

Figure 13. The chemical structure of PEDOT: PSS with the presence of sulfonate ions from an oxidant [94]. 


\subsubsection{Biodegradable Trends of Various Conductive PEDOT-Based Scaffold Composites}

The research focusing on scaffolds for biomedical applications has made significant strides with the advent of new technologies. The mechanical and electrical properties of scaffolds will affect the scaffold's biodegradation rate and biocompatibility [72,95-97]. Wang et al. (2017) experimented with varying weight percentages of PEDOT-HA nanoparticles in the fabrication of hyaluronic acid-doped PEDOT/chitosan/gelation porous conductive scaffolds [9]. They reported that the in vitro biodegradation of the scaffold had an inverse relationship with the weight percentage of PEDOT-HA. The scaffold displayed high biodegradability when there was a minute amount of PEDOT-HA. A large volume of PEDOT-HA enhanced the stability and biodegradation resistance of the scaffold. The addition of hydrophobic PEDOT likely reduced the hydrophilicity of the scaffolds [9].

Table 3. Biodegradation index of various composite scaffolds.

\begin{tabular}{llll}
\hline Scaffold Composition & Scaffold's Biodegradability Claims & Reference \\
\hline & - & CS and nHAp/CS scaffolds showed approximately $30 \%$ weight \\
PEDOT: PSS & loss after 1 month. & PEDOT: PSS/nHAp/CS scaffold degraded with $10 \%$ \\
Chitosan & & $\begin{array}{l}\text { weight loss. } \\
\text { Hydroxyapatite }\end{array}$ \\
Nanoparticles & - & $\begin{array}{l}\text { Incorporation of PEDOT: PSS enhanced the stability of scaffold } \\
\text { in PBS. }\end{array}$
\end{tabular}

- $\quad \mathrm{CS} /$ Gel scaffold showed $86 \%$ weight loss after 8 weeks of

\section{PEDOT}

Hyaluronic acid

Chitosan

Gelatine incubation in lysozyme enzymatic solution.

- $\quad 10 \%$ PEDOT-HA/CS/Gel scaffold experienced $43 \%$ weight loss after 8 weeks of incubation.

- $\quad$ The presence of PEDOT and hyaluronic acid enhanced the stability and biodegradation resistance of scaffolds, due to low water permeability in hydrophobic PEDOT.

- Biodegradation of 0.5 wt.\% PEDOT/CS/Gel scaffold was $72.55 \pm 3.79 \%$ at week 8 in an enzymatic solution.

PEDOT

Chitosan

Gelatine

Hyaluronic acid
- Biodegradation of PEDOT/Cs/Gel scaffold was $59.97 \pm 3.22 \%$, while it was $47.15 \pm 2.17 \%$ for PEDOT-HA/CS gel scaffold.

- The addition of PEDOT lowers the degradation rate of the scaffold.

- $\quad$ PEDOT nanoparticles mediated cell-surface interactions and enhanced cell's growth and proliferation.
- The conductivity of hydrated and dehydrated PEDOT/CS/Gel scaffold gradually decreased over the degradation period.

Chitosan

PEDOT

Gelatine
- Chitosan and gelatine gradually degraded in an enzymatic solution.

- The conductivity value of conductive scaffolds still met the required electrical value for neural tissue engineering application after 8 weeks of incubation time.
Gelatine

Sodium Alginate PEDOT: PSS
- $\quad$ Scaffolds showed $30 \%$ and $70 \%$ weight loss after 7 and 30 days of incubation in DMEM: F12 shaker incubator, respectively.

- There was no significant difference between scaffolds with or without a conductive-polymer.

\section{[9]}


Table 3. Cont.

\begin{tabular}{|c|c|c|}
\hline Scaffold Composition & Scaffold's Biodegradability Claims & Reference \\
\hline $\begin{array}{l}\text { Gellan } \\
\text { PVA }\end{array}$ & $\begin{array}{l}\text { - PG-NFs scaffold was stable and can maintain its structure in } \\
\text { PBS solution for up to } 14 \text { days of incubation. } \\
\text { The initial weight loss is due to non-crosslinked gellan and } \\
\text { PVA molecules. }\end{array}$ & [38] \\
\hline $\begin{array}{l}\text { Polycaprolactone (PCL) } \\
\text { Polypyrrole-block- poly(caprolactone) } \\
\text { (PPy-b-PCL) }\end{array}$ & $\begin{array}{l}\text { - PCL and PCL/PPy } 2 \% \text { scaffolds had degradation rates of } 37.28 \% \\
\text { and } 55.8 \% \text {, respectively. } \\
\text { The degradation rate of the scaffold in the incubator shaker } \\
\text { increased with an increasing PPy-b-PCL concentration. }\end{array}$ & [68] \\
\hline $\begin{array}{l}\text { Hydroxyapatite Collagen I } \\
\text { Chitosan } \\
\text { Glutaraldehyde }\end{array}$ & $\begin{array}{l}\text { - Ha-Col-CS-GTA recorded } 10 \% \text { and } 16 \% \text { weight loss on day } \\
1 \text { and 21, respectively, after incubation for the biodegradation } \\
\text { test using AF-MSCs. } \\
\text { Scaffold without a crosslinker GTA showcased a higher } \\
\text { degradation rate of } 39 \% \text { and } 55 \% \text { after day } 1 \text { and } 21 \text { of } \\
\text { incubation time, respectively. }\end{array}$ & [13]. \\
\hline Polycaprolactone polypyrrole & $\begin{array}{l}\text { - The maximum weight loss of the PCL/chitosan mat was } 20 \% \text { in } \\
\text { PBS solution after } 14 \text { days of incubation. } \\
\text { An amount of } 7.5 \% \text { PPy in the PCL/chitosan mat scaffold } \\
\text { showed } 12 \% \text { weight loss after incubation time. } \\
\text { - Adding PPy into the PCL/chitosan fibres slowed the weight } \\
\text { loss and degradation rate. }\end{array}$ & [78]. \\
\hline $\begin{array}{l}\text { Collagen Chitosan GTA } \\
\text { Genipin TTP }\end{array}$ & $\begin{array}{l}\text { The highest degradation rate }(55.0 \pm 3.78 \%) \text { at day } 21 \text { and } \\
(62.0 \pm 4.23 \%) 28 \text { were recorded on the TPP } \\
\text { crosslinked scaffold. } \\
\text { The GTA solution crosslinked scaffold had the slowest } \\
\text { degradation rate }(17.7 \pm 1.57 \% \text { and } 26.5 \pm 2.98 \%) \text { at day } 21 \text { and } \\
28 \text {, respectively. } \\
\text { The GTA vapour crosslink degradation rate was relatively } \\
\text { higher ( } 3.4 \pm 2.85 \%) \text { on day } 28 \text {. } \\
\text { The higher the crosslinking degree, the lower the } \\
\text { degradation rate. } \\
\text { GP and TPP were only able to crosslink } 78.38 \pm 8.20 \% \text { and } \\
143.27 \pm 4.03 \% \text {, respectively (crosslinking degree between the } \\
\text { crosslinker and collagen/chitosan scaffolds). }\end{array}$ & {$[67]$.} \\
\hline
\end{tabular}

Wang et al. (2017) also researched PEDOT nanoparticles/chitosan/gelatinous porous scaffolds. They claimed that the presence of PEDOT nanoparticles significantly reduced the degradation rate of the scaffolds. Interestingly, the presence of PEDOT nanoparticles in the scaffold increased the cell viability. This is due to the genial interactions between the scaffold and the cell surface, which encourage cell proliferation and growth [40]. Another contribution from Wang et al. (2018) was the study of PEDOT/chitosan/gelatinous scaffolds for neural cells. The electrical conductivity of hydrated and dehydrated PEDOT/chitosan/gel scaffolds gradually diminished over time [10]. This observation could be attributed to the disintegration of the PEDOT layers on the surface of the chitosan/gelatinous matrix. The dissipation of PEDOT layers occurs when chitosan and gelatine are gradually degraded in the presence of the enzymes that are supposed to stimulate physiological conditions. Although the electrical conductivity of the scaffold reduced over time, as summarised in Table 3, it still met the electrical conductivity requirements for electrical stimulation in neural TE application. 
Another study demonstrated that the addition of conductive PEDOT: PSS in nHAp/chitosan composite scaffolds using the lyophilisation method reduced the scaffold's biodegradability rate in the PBS solution. Although the scaffold with PEDOT: PSS had low biodegradability, its mechanical properties were consistent [26]. Lari et al. (2020) attempted to decrease the wettability, while dialling up the mechanical properties, of PEDOT: $\mathrm{PSS} / \mathrm{nHA} / \mathrm{CS}$ biocomposite, by integrating polycaprolactone (PCL) into the scaffold. PCL was selected due to its biodegradability and ease of blending with chitosan [5]. In another study, a PCL-CS-PPy conductive biocomposite nanofibrous scaffold is also a subject of interest in TE. The nanofibrous-structured scaffolds with sufficient biodegradability can be fashioned using electrospinning. It is worth mentioning that the mechanical properties decrease in tandem with the weight percentage of PPy. When the weight percentage of PPy used was reduced, it was easier for the scaffold to disintegrate, exhibiting the non-polymeric scaffold's typical mechanical behaviour [68].

In addition, Abedi et al. (2019) fabricated a conductive nanofibrous chitosan/PEDOT: PSS scaffold using the electrospinning method [25]. They reported that the addition of PEDOT: PSS in the scaffold may support cell growth without any toxic effects. Nonetheless, the biodegradability of the scaffold has yet to be explored. It was reported that the use of PEDOT: PSS in fabricating the scaffold did not change the biodegradability of the scaffold, due to the presence of alginate [98]. In addition, they also stated that an increase in PEDOT: PSS concentration in gelatine-alginate scaffolds could increase cell proliferation, although they did not report the cause. A takeaway from these studies is that the addition of $\mathrm{CPs}$ in the polymer matrix is a prerequisite for acquiring electrically conductive scaffolds. Adjusting the weight percentage of the CPs in the matrix composite of the scaffolds will affect their biodegradability. Therefore, further studies focusing on the relationship between the addition of CPs and the superior biodegradability of conductive scaffolds are warranted.

\subsection{Collagen-Based Scaffolds}

The addition of collagen or silk fibroin in scaffolds as biodegradable substituents can enhance their biodegradability, due to the nature of their proteins. Bioactive molecules, such as collagen, chitosan, and hydroxyapatite (HAp) were described as compatible, nontoxic, non-carcinogenic, non-immunogenic, and soluble in physiological conditions [13]. Due to these properties, the application of a collagen scaffold is prevalent in the field of damaged tissue regeneration [12,13]. Unfortunately, collagen is vulnerable to rapid degradation in body fluid or cell culture media [99]. The breakdown of collagen fibres depends upon the proteolytic action of collagenases, which are part of the large family of matrix metalloproteinases. For type I collagen, the cleavage site is specific, generating threequarter and one-quarter length fragments. These fragments are further degraded by their matrix proteinases, as illustrated in Figure 14. Therefore, it is mandatory to blend collagen with other materials to augment the mechanical properties of collagen-based scaffolds. 


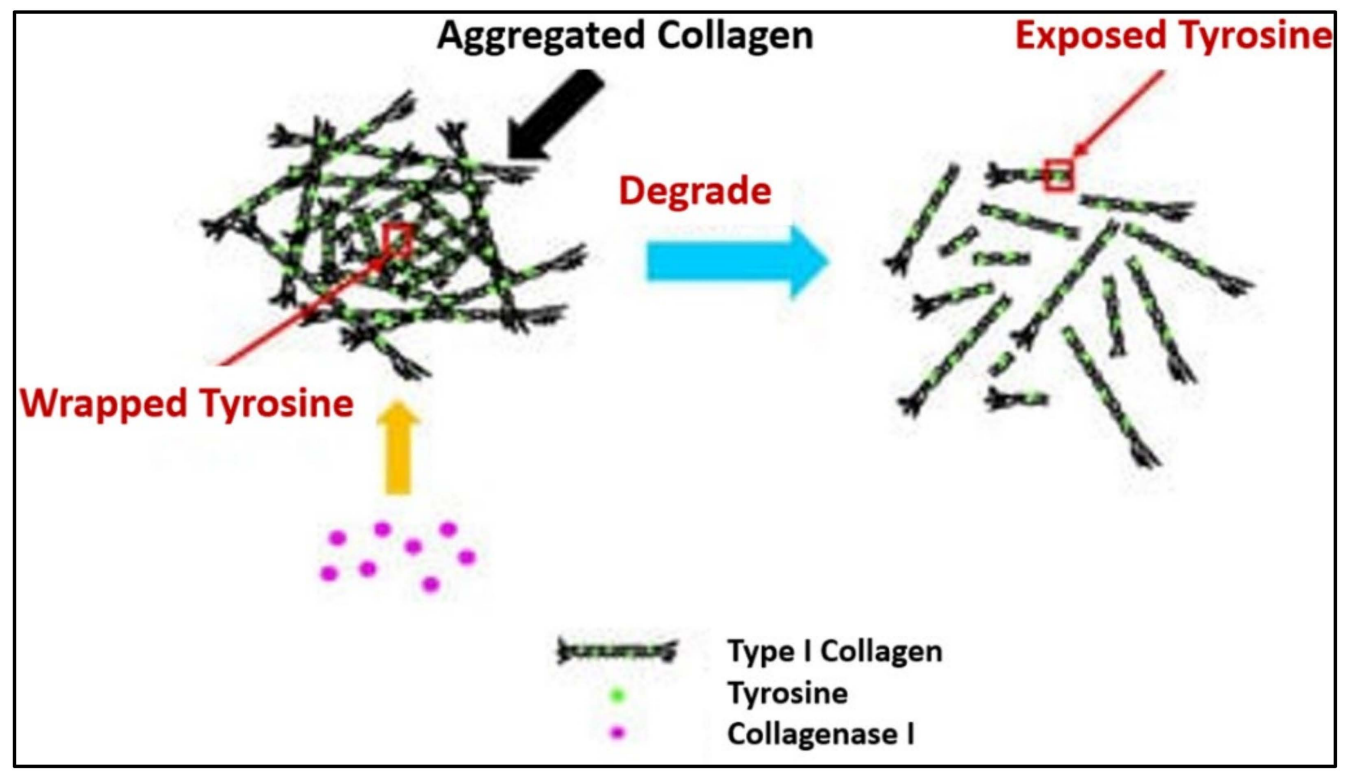

Figure 14. Process of collagen breakdown with the presence of a physiologic collagenase enzyme [100].

\subsection{Chitosan-Based Scaffolds}

Another biodegradable polymer, chitosan, has become relevant in TE, due to its features and properties of low toxicity, non-immunogenic, and biodegradability, that are similar to the native ECM $[5,9,14]$. Chitosan degrades the body through physical and chemical degradation. The former entails swelling, cracking, and dissolution, while chemical degradation results from depolymerisation, oxidation, and hydrolysis [78]. Chitosan behaves as a hydrophilic cation, due to the electronegativity of its amino groups. The deacetylation degree (DA) of chitosan generally influences its polarity, $\mathrm{pH}$, ionic strength and, ultimately, its water-soluble behaviour. Chitosan usually degrades at a $\mathrm{pH}$ below 6 [76]. The breakdown of chitosan through the $\mathrm{pH}$ degradation mechanism is illustrated in Figure 15. Chitosan is a polysaccharide with a cationic nature and displays outstanding properties, such as biocompatibility, hydrophilicity, and anti-thrombogenicity. Furthermore, chitosan can be combined with various polymer materials or drugs, using the appropriate preparation techniques $[4,10,14,18,65,101-103]$. Nonetheless, their mechanical and electrical attributes are unique, depending on their fabrication technique.

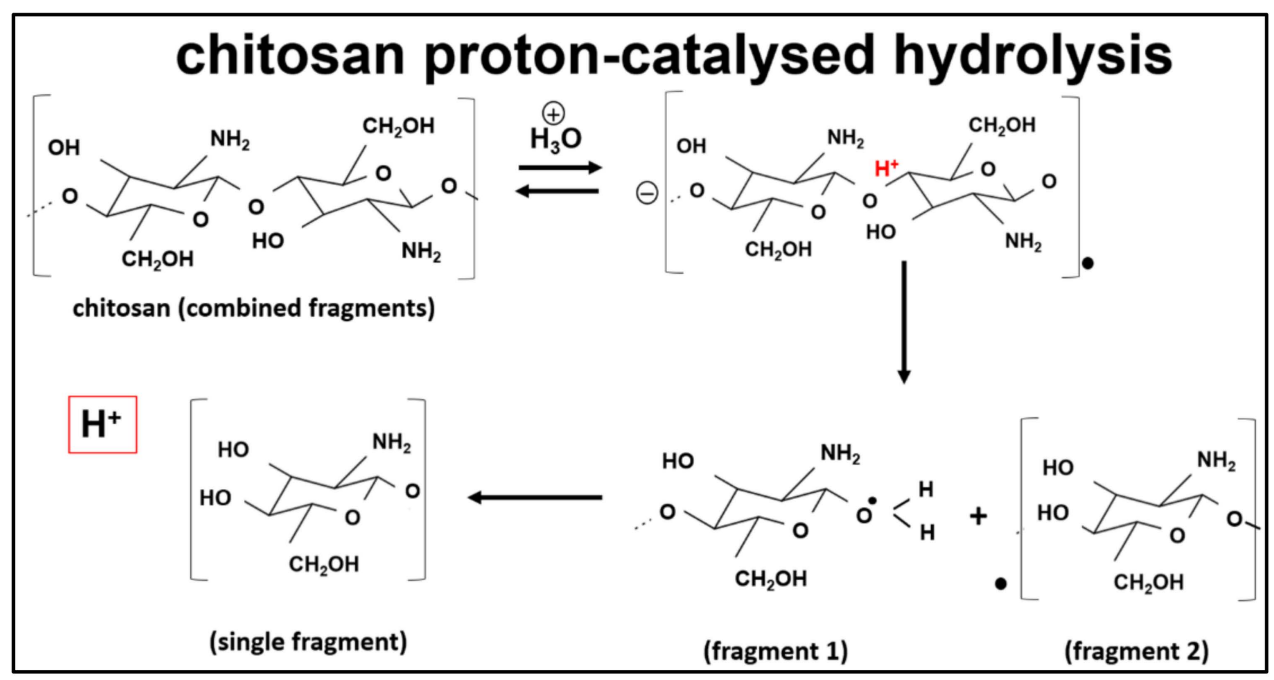

Figure 15. The breakdown of chitosan at $\mathrm{pH} 3$ [76]. 
A study demonstrated that the addition of PEDOT: PSS into chitosan/PVA altered the mechanical properties and conductivity of the scaffold [24]. Conductive polymeric scaffolds with low degradation rates can be turned into composite scaffolds with high degradation rates by mixing them with biodegradable materials. Modifying the CPs backbone by adding typical enzymatically cleavable or hydrolysable linkages between biodegradable materials and CPs backbone also offers a scaffold with a higher biodegradability rate [104]. Table 4 shows a summary of the biodegradation trend of collagen, chitosan, and PEDOT: PSS-based scaffolds.

\section{Current Developments of Polymeric Materials for Biomedical Applications}

CPs hold favourable characteristics, such as electronic-ionic hybrid conductivity, mechanical softness, permeable porosity, and versatile chemical modification. This means they are recommended for a wide range of biomedical applications, including biosensors, chemical sensors, drug delivery systems, artificial muscles, and neural interfaces [105]. Additionally, CPs are utilized in the application of artificial muscles, due to their electrochemical deformation properties. The magnitude of the $\mathrm{CPs}$ ' strain depends upon their number of anions. Briefly, by applying a positive voltage with a suitable electrolyte, the polymer becomes oxidized, and the material loses electrons from the polymer. Then, a pair of anions are formed in the electrolyte. These anions cause the expansion of the polymer. The CP's contraction mechanism (reduction reaction) is similar to the expansion mechanism (oxidation reaction) [106]. In addition, CPs can also be used to replace alkaline metal as biosensors, such as for non-enzymatic glucose sensors, hydrogen peroxide $\left(\mathrm{H}_{2} \mathrm{O}_{2}\right)$ sensors, and dissolved oxygen sensors [107]. Recently, CPs like PANI was reported to have antibacterial properties through a disruption process against the native surface charge of bacterial cells [108]. This finding successfully proved that PANI can be utilized in producing antibacterial medical appliances. However, the use of CPs for skin biosensors was doubted, due to their biocompatibility issues (including inflammation and serious disorders) when in contact with living human physiology [109]. Hence, the utilisation of $\mathrm{CP}$ biomaterials in biomedical applications warrants more research in the near future, since CPs hold several drawbacks alongside their advantageous properties. Table 4 shows the current development of biodegradable natural and synthetic polymeric materials for various biomedical applications, including tissue engineering, temporary implants, wound healing, and drug delivery.

Table 4. Polymeric materials for biomedical applications.

\begin{tabular}{|c|c|c|c|}
\hline Specific Application & Polymer Type & Material & Reference \\
\hline \multirow{4}{*}{ Drug delivery } & Synthetic Biopolymer & poly(lactic-co-glycolic) acid (PLGA) & [110] \\
\hline & Biodegradable natural polymer & chitosan & [111] \\
\hline & Biodegradable natural polymer & kefiran & [112] \\
\hline & Synthetic biopolymer & Poly (ethylene) glycol (PEG) & [113] \\
\hline \multirow{4}{*}{ Tissue Engineering } & Biodegradable natural polymer & gelatine & [94] \\
\hline & Synthetic biopolymer & Polyurethane and modified polyurethane & [114] \\
\hline & Biodegradable natural polymer & collagen & [115] \\
\hline & Synthetic biopolymer & $\begin{array}{l}\text { polyester derivatives, such as poly } \\
\epsilon \text {-caprolactone (PCL), polylactic acid (PLA), } \\
\text { and polyglycolic acid (PGA) }\end{array}$ & [116] \\
\hline \multirow[t]{2}{*}{ Temporary Implants } & Synthetic degradable polymer & $\begin{array}{l}\text { shape memory polymers (with shape } \\
\text { memory effects) }\end{array}$ & [117] \\
\hline & Synthetic biopolymer & poly(lactic) acid (PLA) & [118] \\
\hline \multirow[b]{3}{*}{ Wound Healing } & Biodegradable natural polymer & fibrinogen, hyaluronic acid, cellulose & [119] \\
\hline & Synthetic polymer & polyvinyl alcohol & [120] \\
\hline & Biodegradable natural polymer & $\begin{array}{l}\text { protein derivatives, such as silk; collagen } \\
\text { bacterial polyester, such as bacterial cellulose }\end{array}$ & [121] \\
\hline
\end{tabular}




\section{Conclusions}

Fabrication techniques for conductive and biodegradable scaffolds could affect the physical and mechanical properties of the scaffold. Injectable scaffolds have the potential to be the most suitable low-risk method for TE-related medical treatments. Optimising the scaffold's properties to resemble the properties of human ECM tissue is an ideal goal to realise a scaffold's potential. This will lower the property gap between the scaffold and the tissues at the implantation site. Identical biodegradation and tissue regeneration rates are pivotal to ensure optimised healing. The by-products of scaffolds' degradation should be non-toxic and biocompatible to inhibit immunogenic effects, particularly at the implantable site. In addition to the scaffold's degradation rate, a proof of concept regarding biodegradation should be studied in vivo and in vitro. The biodegradability of CP-based scaffolds should be prioritised, without neglecting their electrical conductivity behaviour in future studies. The uses of CPs in biomedical applications are very broad, and each different $\mathrm{CP}$ has its own potential and speciality. Research, at the basic level, must be carried out, together with a focus on the varied aspects of study environment (in vitro and in vivo studies). This is because human bodies are very complex. Extensive studies focusing on the biocompatibility and immunogenicity of an electrically conductive scaffold composite must be conducted to obtain a clearer view of the use of CPs for tissue engineering applications.

Funding: This work was carried by the NPRP grant \# NPRP11S-1221-170116 from the Qatar National Research Fund (a member of Qatar Foundation). The statements made herein are solely the responsibility of the authors.

Data Availability Statement: Not applicable.

Acknowledgments: The authors wish to thank Norzawani Buang M Yassin, of Imperial College London, United Kingdom, for the useful discussion.

Conflicts of Interest: The authors declare no conflict of interest.

\section{References}

1. Sultana, N.; Chang, H.C.; Jefferson, S.; Daniels, D.E. Application of conductive poly (3,4-ethylenedioxythiophene):poly (styrenesulfonate) (PEDOT:PSS) polymers in potential biomedical engineering. J. Pharm. Investig. 2020, 50, 437-444. [CrossRef]

2. Kaviani, A.; Zebarjad, S.M.; Javadpour, S.; Ayatollahi, M.; Bazargan-Lari, R. Fabrication and characterization of low-cost freeze-gelated chitosan/collagen/hydroxyapatite hydrogel nanocomposite scaffold. Int. J. Polym. Anal. Charact. 2019, 24, 191-203. [CrossRef]

3. O'Brien, F.J. Biomaterials \& scaffolds for tissue engineering. Mater. Today 2011, 14, 88-95. [CrossRef]

4. Roducts, P.; Matica, A.; Ostafe, V. Biodegradability of chitosan based products. New Front. Chem. 2017, 26, 75-86.

5. Lari, A.; Sultana, N.; Soon, C.F. Biocomposites conductive scaffold based on PEDOT: PSS/nHA/Chitosan/PCL: Fabrication and characterization. Malays. J. Fundam. Appl. Sci. 2019, 15, 146-149. [CrossRef]

6. Tamariz, E.; Rios-Ramrez, A. Biodegradation of medical purpose polymeric materials and their impact on biocompatibility. Biodegrad.-Life Sci. 2013, 3-30.

7. Flaig, I.; Radenković, M.; Najman, S.; Pröhl, A.; Jung, O.; Barbeck, M. in vivo analysis of the biocompatibility and immune response of jellyfish collagen scaffolds and its suitability for bone regeneration. Int. J. Mol. Sci. 2020, 21, 4518. [CrossRef]

8. Yang, D.; Xiao, J.; Wang, B.; Li, L.; Kong, X.; Liao, J. The immune reaction and degradation fate of scaffold in cartilage/bone tissue engineering. Mater. Sci. Eng. C 2019, 104, 109927. [CrossRef]

9. Wang, S.; Guan, S.; Zhu, Z.; Li, W.; Liu, T.; Ma, X. Hyaluronic acid doped- poly (3,4-ethylene dioxythiophene)/chitosan/gelatin (PEDOT-HA/Cs/Gel) porous conductive scaffold for nerve regeneration. Mater. Sci. Eng. C 2017, 71, 308-316. [CrossRef] [PubMed]

10. Wang, S.; Guan, S.; Li, W.; Ge, D.; Xu, J.; Sun, C.; Liu, T.; Ma, X. 3D culture of neural stem cells within conductive PEDOT layer-assembled chitosan/gelatin scaffolds for neural tissue engineering. Mater. Sci. Eng. C 2018, 93, 890-901. [CrossRef]

11. Alaribe, F.N.; Manoto, S.L.; Motaung, S.C.K.M. Scaffolds from biomaterials: advantages and limitations in bone and tissue engineering. Biologia 2016, 71,353-366. [CrossRef]

12. Dong, C.; Lv, Y. Application of collagen scaffold in tissue engineering: Recent advances and new perspectives. Polymers 2016, 8, 42. [CrossRef] [PubMed]

13. Rahman, S.; Rana, M.; Spitzhorn, L.-S.; Akhtar, N.; Hasan, Z.; Choudhury, N.; Fehm, T.; Czernuszka, J.T.; Adjaye, J.; Asaduzzaman, S.M. Fabrication of biocompatible porous scaffolds based on hydroxyapatite/collagen/chitosan composite for restoration of defected maxillofacial mandible bone. Prog. Biomater. 2019, 8, 137-154. [CrossRef] [PubMed]

14. Zhang, T.; Jin, L.; Fang, Y.; Lin, F.; Sun, W.; Xiong, Z. Fabrication of biomimetic scaffolds with oriented porous morphology for cardiac tissue engineering. J. Biomater. Tissue Eng. 2014, 4, 1030-1039. [CrossRef] 
15. Plieth, W. Intrinsically conducting polymers. Electrochem. Mater. Sci. 2008, 323-363. [CrossRef]

16. Peng, H.; Sun, X.; Weng, W.; Fang, X. Flexible Electronic Devices Based on Polymers. Polymer Mater. Energy Electron. Appl. 2017, 325-354. [CrossRef]

17. Omar, S.N.I.; Ariffin, Z.Z.; Zakaria, A.; Safian, M.F.; Halim, M.I.A.; Ramli, R.; Sofian, Z.M.; Zulkifli, M.F.; Aizamddin, M.F.; Mahat, M.M. Electrically conductive fabric coated with polyaniline: Physicochemical characterisation and antibacterial assessment. Emergent Mater. 2020, 3, 469-477. [CrossRef]

18. Mawad, D.; Mansfield, C.; Lauto, A.; Perbellini, F.; Nelson, G.W.; Tonkin, J.; Bello, S.O.; Carrad, D.J.; Micolich, A.P.; Mahat, M.M.; et al. A conducting polymer with enhanced electronic stability applied in cardiac models. Sci. Adv. 2016, 2, e1601007. [CrossRef]

19. Liang, Y.; Goh, J.C.-H. Polypyrrole-incorporated conducting constructs for tissue engineering applications: A review. Bioelectricity 2020, 2, 101-119. [CrossRef]

20. Palza, H.; Zapata, P.A.; Angulo-Pineda, C. Electroactive smart polymers for biomedical applications. Materials 2019, $12,277$. [CrossRef]

21. Jadoun, S.; Riaz, U.; Budhiraja, V. Biodegradable conducting polymeric materials for biomedical applications: A review. Med. Devices Sens. 2021, 4, e10141. [CrossRef]

22. Dubey, N.; Kushwaha, C.S.; Shukla, S.K. A review on electrically conducting polymer bionanocomposites for biomedical and other applications. Int. J. Polym. Mater. Polym. Biomater. 2019, 69, 709-727. [CrossRef]

23. Prasopthum, A.; Deng, Z.; Khan, I.M.; Yin, Z.; Guo, B.; Yang, J. Biomaterials science three dimensional printed degradable and conductive polymer scaffolds promote chondrogenic differentiation. Biomater. Sci. 2020, 8, 4287-4298. [CrossRef]

24. Da Silva, A.C.; Córdoba de Torresi, S.I. Advances in conducting, biodegradable and biocompatible copolymers for biomedical applications. Front. Mater. 2019, 6, 1-9. [CrossRef]

25. Abedi, A.; Hasanzadeh, M.; Tayebi, L. Conductive nanofibrous Chitosan/PEDOT: PSS tissue engineering scaffolds. Mater. Chem. Phys. 2019, 237, 121882. [CrossRef]

26. Lari, A.; Sun, T.; Sultana, N. PEDOT: PSS-containing nanohydroxyapatite/chitosan conductive bionanocomposite scaffold: Fabrication and evaluation. J. Nanomater. 2016, 2016, 1-12. [CrossRef]

27. Lončarević, A.; Ivanković, M.; Rogina, A. Lysozyme-induced degradation of chitosan: The characterisation of degraded chitosan scaffolds. J. Tissue Repair Regen. 2017, 1, 12-22. [CrossRef]

28. Dhandayuthapani, B.; Yoshida, Y.; Maekawa, T.; Kumar, D.S. Polymeric scaffolds in tissue engineering application: A review. Int. J. Polym. Sci. 2011, 2011, 1-19. [CrossRef]

29. Wang, S.; Lei, J.; Yi, X.; Yuan, L.; Ge, L.; Li, D.; Mu, C. Fabrication of polypyrrole-grafted gelatin-based hydrogel with conductive, self-healing, and injectable properties. ACS Appl. Polym. Mater. 2020, 2, 3016-3023. [CrossRef]

30. Iandolo, D.; Sheard, J.; Levy, G.K.; Pitsalidis, C.; Tan, E.; Dennis, A.; Kim, J.-S.; Markaki, A.E.; Widera, D.; Owens, R.M.; et al. Biomimetic and electroactive 3D scaffolds for human neural crest-derived stem cell expansion and osteogenic differentiation. MRS Commun. 2020, 10, 179-187. [CrossRef]

31. Akbarzadeh, R.; Yousefi, A.-M. Effects of processing parameters in thermally induced phase separation technique on porous architecture of scaffolds for bone tissue engineering. J. Biomed. Mater. Res. Part B Appl. Biomater. 2014, 102, 1304-1315. [CrossRef]

32. Wade, R.J.; Burdick, J.A. Engineering ECM signals into biomaterials. Mater. Today 2012, 15, 454-459. [CrossRef]

33. Roshanbinfar, K.; Vogt, L.; Greber, B.; Diecke, S.; Boccaccini, A.R.; Scheibel, T.; Engel, F.B. Electroconductive biohybrid hydrogel for enhanced maturation and beating properties of engineered cardiac tissues. Adv. Funct. Mater. 2018, 28, 1803951. [CrossRef]

34. Conoscenti, G.; La Carrubba, V.; Brucato, V. A versatile technique to produce porous polymeric scaffolds: The thermally induced phase separation (TIPS) method. Arch. Chem. Res. 2017, 1, 10-20. [CrossRef]

35. Lee, J.K.; Link, J.M.; Hu, J.C.Y.; Athanasiou, K.A. The self-assembling process and applications in tissue engineering. Cold Spring Harb. Perspect. Med. 2017, 7, a025668. [CrossRef]

36. Wang, L.; Wu, Y.; Hu, T.; Guo, B.; Ma, P.X. Electrospun conductive nanofibrous scaffolds for engineering cardiac tissue and 3D bioactuators. Acta Biomater. 2017, 59, 68-81. [CrossRef]

37. Aadil, K.R.; Nathani, A.; Sharma, C.S.; Lenka, N.; Gupta, P. Investigation of poly (vinyl) alcohol-gellan gum based nanofiber as scaffolds for tissue engineering applications. J. Drug Deliv. Sci. Technol. 2019, 54, 101276. [CrossRef]

38. Tseghai, G.B.; Mengistie, D.A.; Malengier, B.; Fante, K.A.; Van Langenhove, L. PEDOT: PSS-based conductive textiles and their applications. Sensors 2020, 20, 1881. [CrossRef]

39. Rahmani, A.; Nadri, S.; Kazemi, H.S.; Mortazavi, Y.; Sojoodi, M. Conductive electrospun scaffolds with electrical stimulation for neural differentiation of conjunctiva mesenchymal stem cells. Artif. Organs 2019, 43, 780-790. [CrossRef]

40. Dong, S.; Han, L.; Du, C.; Wang, X.; Li, L.; Wei, Y. 3D printing of aniline tetramer-grafted-polyethylenimine and pluronic F127 composites for electroactive scaffolds. Macromol. Rapid Commun. 2017, 38, 1600551. [CrossRef] [PubMed]

41. Fani, N.; Hajinasrollah, M.; Vostikolaee, M.A.; Eslaminejad, M.B.; Mashhadiabbas, F.; Tongas, N.; Rasoulianboroujeni, M.; Yadegari, A.; Ede, K.; Tahriri, M.; et al. Influence of conductive PEDOT: PSS in a hard tissue scaffold: In vitro and in vivo study. J. Bioact. Compat. Polym. 2019, 34, 436-441. [CrossRef]

42. Wang, S.; Sun, C.; Guan, S.; Li, W.; Xu, J.; Ge, D.; Zhuang, M.; Liu, T.; Ma, X. Chitosan/gelatin porous scaffolds assembled with conductive poly (3, 4-ethylenedioxythiophene) nanoparticles for neural tissue engineering. J. Mater. Chem. B 2017, 5, 4774-4788. [CrossRef] [PubMed] 
43. Pourjavadi, A.; Doroudian, M.; Ahadpour, A.; Azari, S. Injectable chitosan/ —carrageenan hydrogel designed with au nanoparticles: A conductive scaffold for tissue engineering demands. Int. J. Biol. Macromol. 2019, 126, 310-317. [CrossRef] [PubMed]

44. Athukorala, S.; Tran, T.; Balu, R.; Truong, V.; Chapman, J.; Dutta, N.; Choudhury, N. 3D printable electrically conductive hydrogel scaffolds for biomedical applications: A review. Polymers 2021, 13, 474. [CrossRef] [PubMed]

45. Omar, M.H.; Razak K., A.; Ab Wahab, M.N.; Hamzah, H.H. Recent progress of conductive 3D printed electrodes based upon polymers/carbon nanomaterials using a fused deposition modelling (FDM) method as emerging electrochemical sensing devices. RSC Adv. 2021, 11, 16557-16571. [CrossRef]

46. Lu, B.; Yuk, H.; Lin, S.; Jian, N.; Qu, K.; Xu, J.; Zhao, X. Pure PEDOT: PSS hydrogels. Nat. Commun. 2019, 10, 1-10. [CrossRef]

47. Gao, Q.; Wang, M.; Kang, X.; Zhu, C.; Ge, M. Continuous wet-spinning of flexible and water-stable conductive PEDOT: PSS/PVA composite fibres for wearable sensors. Compos. Commun. 2020, 17, 134-140. [CrossRef]

48. Zhang, L.; Yang, K.; Chen, R.; Zhou, Y.; Chen, S.; Zheng, Y.; Li, M.; Xu, C.; Tang, X.; Zang, Z.; et al. The role of mineral acid doping of PEDOT: PSS and its application in organic photovoltaics. Adv. Electron. Mater. 2020, 6, 1900648. [CrossRef]

49. Pathak, C.S.; Singh, J.P.; Singh, R. Effect of dimethyl sulfoxide on the electrical properties of PEDOT: PSS/n-Si heterojunction diodes. Curr. Appl. Phys. 2015, 15, 528-534. [CrossRef]

50. Ouyang, L.; Musumeci, C.; Jafari, M.J.; Ederth, T.; Inganäs, O. Imaging the phase separation between PEDOT and polyelectrolytes during processing of highly conductive PEDOT: PSS films. ACS Appl. Mater. Interfaces 2015, 7, 19764-19773. [CrossRef]

51. Sun, Y.; Yang, S.; Du, P.; Yan, F.; Qu, J.; Zhu, Z.; Zuo, J.; Zhang, C. Investigate the effects of EG doping PEDOT/PSS on transmission and anti-reflection properties using terahertz pulsed spectroscopy. Opt. Express 2017, 25, 1723-1731. [CrossRef] [PubMed]

52. Kim, T.; Park, S.; Seo, J.; Lee, C.W.; Kim, J.-M. Highly conductive PEDOT: PSS with enhanced chemical stability. Org. Electron. 2019, 74, 77-81. [CrossRef]

53. Li, S.; Tao, Y.; Maryum, P.; Wang, Q.; Zhu, J.; Min, F.; Cheng, H.; Zhao, S.; Wang, C. Bifunctional polyaniline electroconductive hydrogels with applications in supercapacitor and wearable strain sensors. J. Biomater. Sci. Polym. Ed. 2020, 31, 938-953. [CrossRef]

54. Omar, S.; Ariffin, Z.; Akhir, R.; Shri, D.; Halim, M.; Safian, M.; Azman, H.; Ramli, R.; Mahat, M. Polyaniline (PANI) fabric doped p-toluene sulfonic acid (pTSA) with anti-infection properties. Mater. Today Proc. 2019, 16, 1994-2002. [CrossRef]

55. Mawad, D.; Artzy-Schnirman, A.; Tonkin, J.; Ramos, J.; Inal, S.; Mahat, M.M.; Darwish, N.; Zwi-Dantsis, L.; Malliaras, G.; Gooding, J.J.; et al. Electroconductive hydrogel based on functional poly (Ethylenedioxy Thiophene). Chem. Mater. 2016, 28, 6080-6088. [CrossRef]

56. Valenzuela-Rojo, R.D.; López-Cervantes, J.; Sánchez-Machado, D.I.; Escárcega-Galaz, A.A.; Macias, M.D.R.M. Antibacterial, mechanical and physical properties of collagen - chitosan sponges from aquatic source. Sustain. Chem. Pharm. 2020, 15, 100218. [CrossRef]

57. Zhang, C.; Hsieh, M.-H.; Wu, S.-Y.; Li, S.-H.; Wu, J.; Liu, S.-M.; Wei, H.-J.; Weisel, R.D.; Sung, H.-W.; Li, R.-K. A self-doping conductive polymer hydrogel that can restore electrical impulse propagation at myocardial infarct to prevent cardiac arrhythmia and preserve ventricular function. Biomaterials 2020, 231, 119672. [CrossRef]

58. Rowland, C.R.; Lennon, D.P.; Caplan, A.; Guilak, F. The effects of crosslinking of scaffolds engineered from cartilage ECM on the chondrogenic differentiation of MSCs. Biomaterials 2013, 34, 5802-5812. [CrossRef]

59. Davidenko, N.; Bax, D.V.; Schuster, C.F.; Farndale, R.W.; Hamaia, S.W.; Best, S.M.; Cameron, R.E. Optimisation of UV irradiation as a binding site conserving method for crosslinking collagen-based scaffolds. J. Mater. Sci. Mater. Med. 2016, 27, 1-17. [CrossRef]

60. Haugh, M.G.; Murphy, C.M.; McKiernan, R.C.; Altenbuchner, C.; O’Brien, F.J. Crosslinking and mechanical properties significantly influence cell attachment, proliferation, and migration within collagen glycosaminoglycan scaffolds. Tissue Eng.-Part A 2011, 17, 1201-1208. [CrossRef]

61. Ramli, J.; Hadi, A.S.; Jeefferie, A.R.; Mahat, M.M. A preliminary study on the effects of photoinitiator and UV curing exposure time to the mechanical and physical properties of the epoxy and vinyl ester fibreglass laminated composites. Int. J. Eng. Technol. 2010, 1, 14-20.

62. Campiglio, C.E.; Negrini, N.C.; Farè, S.; Draghi, L. Cross-linking strategies for electrospun gelatin scaffolds. Materials 2019, 12, 2476. [CrossRef]

63. Saidin, S.; Jumat, M.A.; Amin, N.A.A.M.; Al-Hammadi, A.S.S. Organic and inorganic antibacterial approaches in combating bacterial infection for biomedical application. Mater. Sci. Eng. C 2020, 118, 111382. [CrossRef]

64. Rizeq, B.R.; Younes, N.N.; Rasool, K.; Nasrallah, G.K. Synthesis, bioapplications, and toxicity evaluation of chitosan-based nanoparticles. Int. J. Mol. Sci. 2019, 20, 5776. [CrossRef] [PubMed]

65. Islam, N.; Wang, H.; Maqbool, F.; Ferro, V. In vitro enzymatic digestibility of glutaraldehyde-crosslinked chitosan nanoparticles in lysozyme solution and their applicability in pulmonary drug delivery. Molecules 2019, 24, 1271. [CrossRef]

66. Hua, Y.; Ma, C.; Wei, T.; Zhang, L.; Shen, J. Collagen/chitosan complexes: Preparation, antioxidant activity, tyrosinase inhibition activity, and melanin synthesis. Int. J. Mol. Sci. 2020, 21, 313. [CrossRef] [PubMed]

67. Fang, Y.; Zhang, T.; Song, Y.; Sun, W. Assessment of various crosslinking agents on collagen/chitosan scaffolds for myocardial tissue engineering. Biomed. Mater. 2020, 15, 045003. [CrossRef]

68. VijayaVenkataRaman, S.; Kannan, S.; Cao, T.; Fuh, J.Y.H.; Sriram, G.; Lu, W.F. 3D-printed PCL/PPy conductive scaffolds as three-dimensional porous nerve guide conduits (NGCs) for peripheral nerve injury repair. Front. Bioeng. Biotechnol. 2019, 7, 266. [CrossRef] [PubMed] 
69. Söntjens, S.; Nettles, D.L.; Carnahan, M.A.; Setton, L.A.; Grinstaff, M. Biodendrimer-based hydrogel scaffolds for cartilage tissue repair. Biomacromolecules 2006, 7, 310-316. [CrossRef]

70. Lu, T.; Hu, H.; Li, Y.; Jiang, Q.; Su, J.; Lin, H.; Xiao, Y.; Zhu, X.; Zhang, X. Bioactive scaffolds based on collagen filaments with tunable physico-chemical and biological features. Soft Matter 2020, 16, 4540-4548. [CrossRef] [PubMed]

71. Qu, H.; Fu, H.; Han, Z.; Sun, Y. Biomaterials for bone tissue engineering scaffolds: a review. RSC Adv. 2019, 9, $26252-26262$. [CrossRef]

72. Zhang, X.; Thomas, V.; Vohra, Y.K. In vitro biodegradation of designed tubular scaffolds of electrospun protein/polyglyconate blend fibers. J. Biomed. Mater. Res. Part B Appl. Biomater. 2008, 89, 135-147. [CrossRef]

73. Zhang, F.; King, M.W. Biodegradable polymers as the pivotal player in the design of tissue engineering scaffolds. Adv. Health Mater. 2020, 9, e1901358. [CrossRef] [PubMed]

74. Schedl, L.; von Burkersroda, F.; Gopferich, A. Why degradable polymers undergo surface erosion or bulk erosion. Biomaterials 2002, 23, 4221-4231. [CrossRef]

75. Woodard, L.N.; Grunlan, M.A. Hydrolytic degradation and erosion of polyester biomaterials. ACS Macro Lett. 2018, 7, 976-982 [CrossRef]

76. Guarino, V.; Caputo, T.; Altobelli, R.; Ambrosio, L. Degradation properties and metabolic activity of alginate and chitosan polyelectrolytes for drug delivery and tissue engineering applications. AIMS Mater. Sci. 2015, 2, 497-502. [CrossRef]

77. Ding, Y.; Invernale, M.A.; Sotzing, G.A. Conductivity trends of PEDOT-PSS impregnated fabric and the effect of conductivity on electrochromic textile. ACS Appl. Mater. Interfaces 2010, 2, 1588-1593. [CrossRef]

78. Talebi, A.; Labbaf, S.; Karimzadeh, F. Polycaprolactone-chitosan-polypyrrole conductive biocomposite nanofibrous scaffold for biomedical applications. Polym. Compos. 2019, 41, 645-652. [CrossRef]

79. Sarkar, S.; Baker, B.A.; Chen, D.; Pine, P.S.; McDaniel, J.H.; Salit, M.L.; Losert, W.; Simon, G.G.; Dunkers, J. Roles of nanofiber scaffold structure and chemistry in directing human bone marrow stromal cell response. Adv. Tissue Eng. Regen. Med. 2016, 1, 00003. [CrossRef]

80. Cauich-Rodríguez, J.V.; Chan-Chan, L.H.; Hernandez-Sánchez, F.; Cervantes-Uc, J.M. Degradation of polyurethanes for cardiovascular applications. Adv. Biomater. Sci. Biomed. Appl. 2013, 51-82. [CrossRef]

81. Volsi, A.L.; Tallia, F.; Iqbal, H.; Georgiou, T.K.; Jones, J.R. Enzyme degradable star polymethacrylate/silica hybrid inks for 3D printing of tissue scaffolds. Mater. Adv. 2020, 1, 3189-3199. [CrossRef]

82. Tang, H.; Zhao, W.; Yu, J.; Li, Y.; Zhao, C. Recent development of pH-responsive polymers for cancer nanomedicine. Molecules 2019, 24, 4. [CrossRef]

83. Zech, J.; Mader, M.; Gündel, D.; Metz, H.; Odparlik, A.; Agarwal, S.; Mader, K.; Greiner, A. Noninvasive characterization (EPR, $\mu \mathrm{CT}, \mathrm{NMR}$ ) of 3D PLA electrospun fibre sponges for controlled drug delivery. Int. J. Pharm. X 2020, 2, 100055.

84. Hamedani, Y.; Teixeira, R.B.; Karbasiafshar, C.; Wipf, P.; Bhowmick, S.; Abid, M.R. Delivery of a mitochondria-targeted antioxidant from biocompatible, polymeric nanofibrous scaffolds. FEBS Open Bio 2020, 11, 35-47. [CrossRef] [PubMed]

85. Talacua, H.; Söntjens, S.H.M.; Thakkar, S.H.; Brizard, A.M.A.; van Herwerden, L.A.; Vink, A.; van Almen, G.C.; Dankers, P.Y.W.; Bouten, C.V.C.; Budde, R.P.J.; et al. Imaging the in vivo degradation of tissue engineering implants by use of supramolecular radiopaque biomaterials. Macromol. Biosci. 2020, 20, 2000024. [CrossRef] [PubMed]

86. Leng, X.; Liu, B.; Su, B.; Liang, M.; Shi, L.; Li, S.; Qu, S.; Fu, X.; Liu, Y.; Yao, M.; et al. In situ ultrasound imaging of silk hydrogel degradation and neovascularization. J. Tissue Eng. Regen. Med. 2015, 11, 822-830. [CrossRef] [PubMed]

87. Kim, S.H.; Park, J.H.; Kwon, J.S.; Cho, J.G.; Park, K.G.; Park, C.H.; Yoo, J.J.; Atala, A.; Choi, H.S.; Kim, M.S.; et al. NIR fluorescence for monitoring in vivo scaffold degradation along with stem cell tracking in bone tissue engineering. Biomaterials 2020, 258, 120267. [CrossRef]

88. Gil, C.J.; Tomov, M.L.; Theus, A.S.; Cetnar, A.; Mahmoudi, M.; Serpooshan, V. In vivo tracking of tissue-engineered constructs. Micromachines 2019, 10, 474. [CrossRef]

89. Zhang, M.; Wang, Z.; Huang, P.; Jiang, G.; Xu, C.; Zhang, W.; Guo, R.; Li, W.; Zhang, X. Real-time and noninvasive tracking of injectable hydrogel degradation using functionalized AIE nanoparticles. Nanophotonics 2020, 9, 2063-2075. [CrossRef]

90. Agrawal, C.M.; Athanasiou, K.A. Technique to control pH in vicinity of biodegrading PLA-PGA implants. J. Biomed. Mater. Res. 1997, 38, 105-114. [CrossRef]

91. Meng, Z.; He, J.; Li, J.; Su, Y.; Li, D. Melt-based, solvent-free additive manufacturing of biodegradable polymeric scaffolds with designer microstructures for tailored mechanical/biological properties and clinical applications. Virtual Phys. Prototyp. 2020, 15, 417-444. [CrossRef]

92. Szymczyk-Ziółkowska, P.; Łabowska, M.B.; Detyna, J.; Michalak, I.; Gruber, P. A review of fabrication polymer scaffolds for biomedical applications using additive manufacturing techniques. Biocybern. Biomed. Eng. 2020, 40, 624-638. [CrossRef]

93. Kayser, L.V.; Lipomi, D.J. Stretchable conductive polymers and composites based on PEDOT and PEDOT: PSS. Adv. Mater. 2019, 31, e1806133. [CrossRef]

94. Ruzaidi, D.A.A.; Mahat, M.M.; Sofian, Z.M.; Hashim, N.A.N.; Osman, H.; Nawawi, M.A.; Ramli, R.; Jantan, K.A.; Aizamddin, M.F.; Azman, H.H.; et al. Synthesis and Characterization of Porous, Electro-Conductive Chitosan-GelatinAgar-Based PEDOT: PSS Scaffolds for Potential Use in Tissue Engineering. Polymers 2021, 13, 2901. [CrossRef]

95. Feng, P.; Wu, P.; Gao, C.; Yang, Y.; Guo, W.; Yang, W.; Shuai, C. A multimaterial scaffold with tunable properties: Toward bone tissue repair. Adv. Sci. 2018, 5, 1700817. [CrossRef] [PubMed] 
96. Sarvari, R.; Akbari-Alanjaraghi, M.; Massoumi, B.; Beygi-Khosrowshahi, Y.; Agbolaghi, S. Conductive and biodegradable scaffolds based on a five-arm and functionalized star-like polyaniline-polycaprolactone copolymer with a d -glucose core. N. J. Chem. 2017, 41, 6371-6384. [CrossRef]

97. Ghosh, S.; Haldar, S.; Gupta, S.; Bisht, A.; Chauhan, S.; Kumar, V.; Roy, P.; Lahiri, D. Anisotropically conductive biodegradable scaffold with coaxially aligned carbon nanotubes for directional regeneration of peripheral nerves. ACS Appl. Bio Mater. 2020, 3 , 5796-5812. [CrossRef]

98. Mahmoudinezhad, M.H.; Karkhaneh, A.; Jadidi, K. Effect of PEDOT: PSS in tissue engineering composite scaffold on improvement and maintenance of endothelial cell function. J. Biosci. 2018, 43, 307-319. [CrossRef] [PubMed]

99. Peng, L.; Xiang, R.C.; Jia, W.W.; Dong, X.X.; Wang, G. Preparation and evaluation of porous chitosan/collagen scaffolds for periodontal tissue engineering. J. Bioact. Compat. Polym. 2006, 21, 207-220. [CrossRef]

100. Shen, Y.; Zhu, D.; Lu, W.; Liu, B.; Li, Y.; Cao, S. The characteristics of intrinsic fluorescence of type I collagen influenced by collagenase I. Appl. Sci. 2018, 8, 1947. [CrossRef]

101. Talebi, A.; Labbaf, S.; Karimzadeh, F. A conductive film of chitosan- polycaprolactone-polypyrrole with potential in heart patch application. Polym. Test. 2019, 75, 254-261. [CrossRef]

102. Hardiansyah, A.; Tanadi, H.; Yang, M.-C.; Liu, T.-Y. Electrospinning and antibacterial activity of chitosan-blended poly (lactic acid) nanofibers. J. Polym. Res. 2015, 22,1-10. [CrossRef]

103. Xu, T.; Yang, H.; Yang, D.; Yu, Z.Z. Polylactic acid nanofiber scaffold decorated with chitosan island like topography for bone tissue engineering. ACS Appl. Mater. Interfaces 2017, 9, 21094-21104. [CrossRef]

104. Boehler, C.; Aqrawe, Z.; Asplund, M. Applications of PEDOT in bioelectronic medicine. Bioelectron. Med. 2019, 2, 89-99. [CrossRef]

105. Lee, S.; Ozlu, B.; Eom, T.; Martin, D.C.; Shim, B.S. Electrically conducting polymers for bio-interfacing electronics: From neural and cardiac interfaces to bone and artificial tissue biomaterials. Biosens. Bioelectron. 2020, 170, 112620. [CrossRef] [PubMed]

106. Namsheer, K.; Rout, C.S. Conducting polymers: A comprehensive review on recent advances in synthesis, properties and applications. RSC Adv. 2021, 11, 5659-5697. [CrossRef]

107. Shafiee, S.A.; Perry, S.C.; Hamzah, H.H.; Mahat, M.M.; Al-Lolage, F.A.; Ramli, M.Z. Recent advances on metal nitride materials as emerging electrochemical sensors: A mini review. Electrochem. Commun. 2020, 120, 106828. [CrossRef]

108. Mahat, M.M.; Sabere, A.S.M.; Azizi, J.; Amdan, N.A.N. Potential Applications of Conducting Polymers to Reduce Secondary Bacterial Infections among COVID-19 Patients. A Review. Emergent Mater. 2021, 1-14. [CrossRef]

109. Ramanavicius, S.; Ramanavicius, A. Conducting polymers in the design of biosensors and biofuel cells. Polymers 2020, 13, 49. [CrossRef]

110. Lim, H.; Ha, S.; Bae, M.; Yoon, S.H. A highly robust approach to fabricate the mass-customizable mould of sharp-tipped biodegradable polymer microneedles for drug delivery. Int. J. Pharm. 2021, 600, 120475. [CrossRef]

111. Ahmad, S.; Abbasi, A.; Manzoor, K.; Mangla, D.; Aggarwal, S.; Ikram, S. Chitosan-based bionanocomposites in drug delivery In Bionanocomposites in Tissue Engineering and Regenerative Medicine; Woodhead Publishing Series in Biomaterials; Woodhead Publishing: Sawston, UK, 2021; pp. 187-203.

112. Tan, K.-X.; Chamundeswari, V.N.; Loo, S.C.J. Prospects of kefiran as a food-derived biopolymer for agri-food and biomedical applications. RSC Adv. 2020, 10, 25339-25351. [CrossRef]

113. Englert, C.; Brendel, J.C.; Majdanski, T.C.; Yildirim, T.; Schubert, S.; Gottschaldt, M.; Windhab, N.; Schubert, U.S. Pharmapolymers in the 21st century: Synthetic polymers in drug delivery applications. Prog. Polym. Sci. 2018, 87, 107-164. [CrossRef]

114. Naureen, B.; Haseeb, A.; Basirun, W.; Muhamad, F. Recent advances in tissue engineering scaffolds based on polyurethane and modified polyurethane. Mater. Sci. Eng. C 2020, 118, 111228. [CrossRef]

115. Perez-Puyana, V.; Jiménez-Rosado, M.; Romero, A.; Guerrero, A. Fabrication and Characterization of Hydrogels Based on Gelatinised Collagen with Potential Application in Tissue Engineering. Polymers 2020, 12, 1146. [CrossRef]

116. Asadi, N.; Del Bakhshayesh, A.R.; Davaran, S.; Akbarzadeh, A. Common biocompatible polymeric materials for tissue engineering and regenerative medicine. Mater. Chem. Phys. 2019, 242, 122528. [CrossRef]

117. Holman, H.; Kavarana, M.N.; Rajab, T.K. Smart materials in cardiovascular implants: Shape memory alloys and shape memory polymers. Artif. Organs 2020, 45, 454-463. [CrossRef] [PubMed]

118. Da Silva, D.; Kaduri, M.; Poley, M.; Adir, O.; Krinsky, N.; Shainsky-Roitman, J.; Schroeder, A. Biocompatibility, biodegradation and excretion of polylactic acid (PLA) in medical implants and theranostic systems. Chem. Eng. J. 2018, 340, 9-14. [CrossRef]

119. Bombin, A.D.J.; Dunne, N.J.; McCarthy, H.O. Electrospinning of natural polymers for the production of nanofibres for wound healing applications. Mater. Sci. Eng. C 2020, 114, 110994. [CrossRef] [PubMed]

120. Shende, P.; Gupta, H. Formulation and comparative characterization of nanoparticles of curcumin using natural, synthetic and semi-synthetic polymers for wound healing. Life Sci. 2020, 253, 117588. [CrossRef]

121. Puertas-Bartolomé, M.; Mora-Boza, A.; García-Fernández, L. Emerging biofabrication techniques: A review on natural polymers for biomedical applications. Polymers 2021, 13, 1209. [CrossRef] [PubMed] 